\title{
Observation of cyclonic eddies during the REEBUS experiment
}

Tim Fischer, Johannes Karstensen,1 Marcus Dengler, 1 Arne Bendinger ${ }^{2}$

${ }^{1}$ GEOMAR Helmholtz Centre for Ocean Research Kiel, ${ }^{2}$ LEGOS Toulouse, contact: tfischer@geomar.de

A

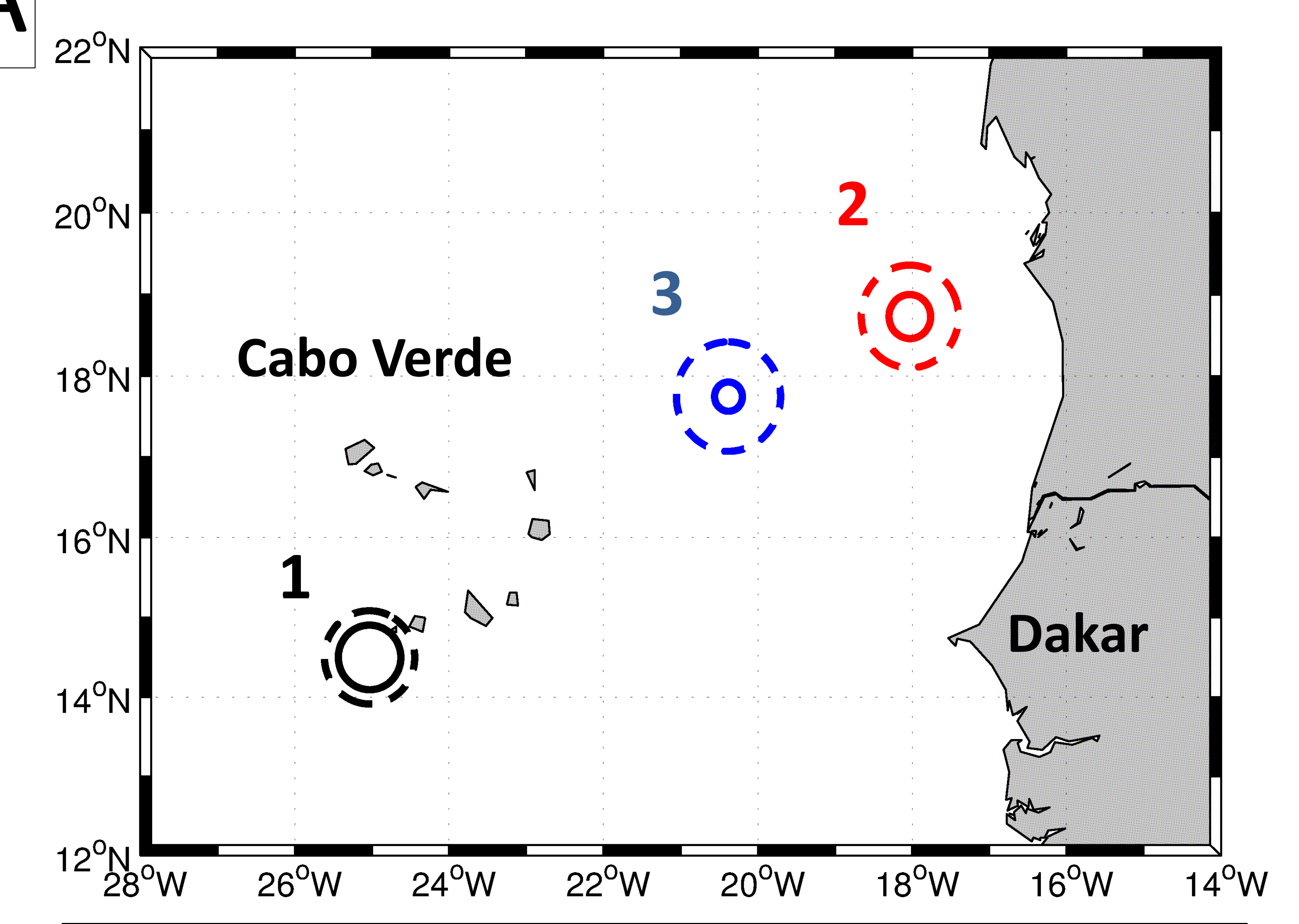

\section{B Azimutal velocity vs. radius B (at $15 \mathrm{~m}$ to $45 \mathrm{~m}$ depth)}

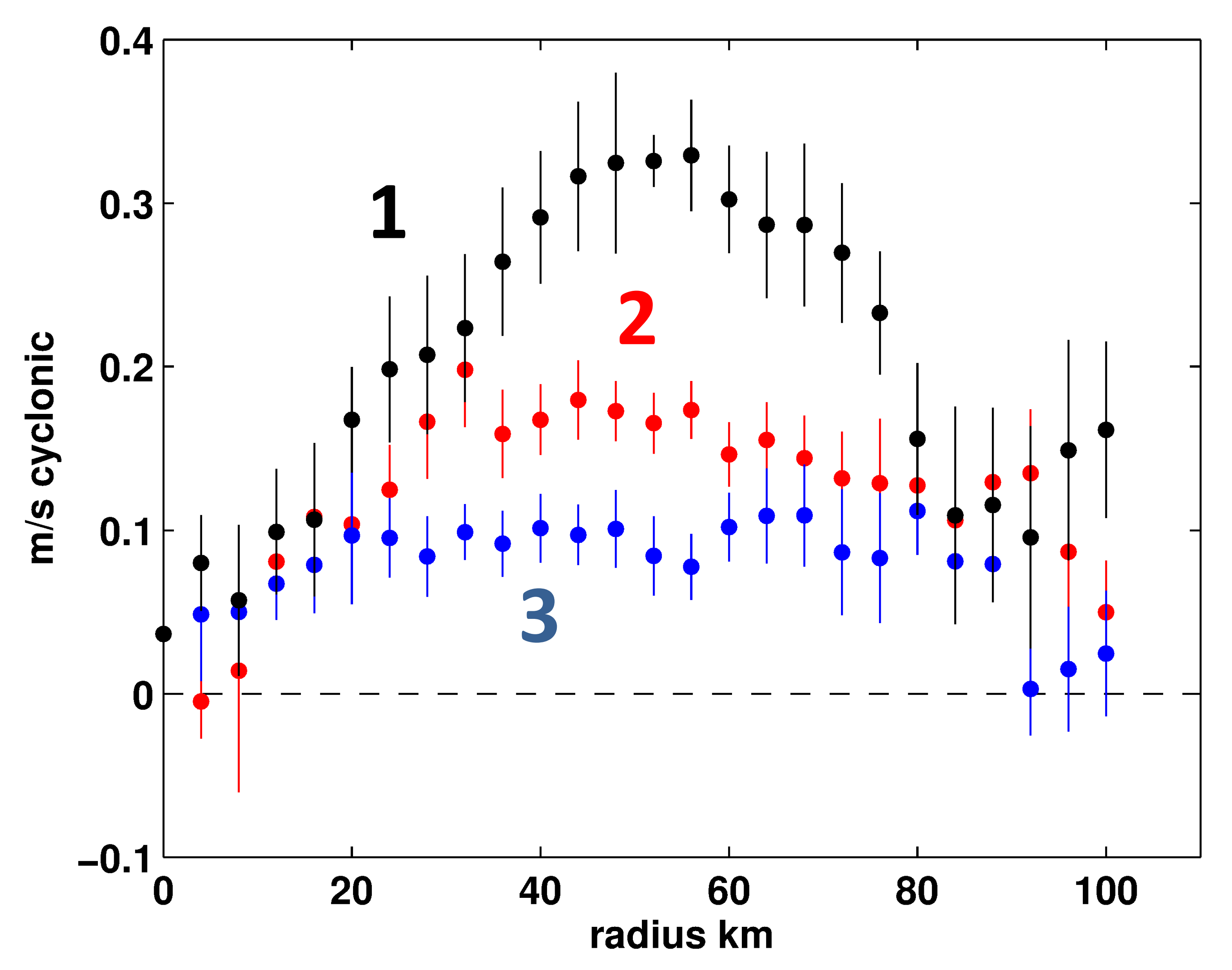

Eddy 1 vertical structure

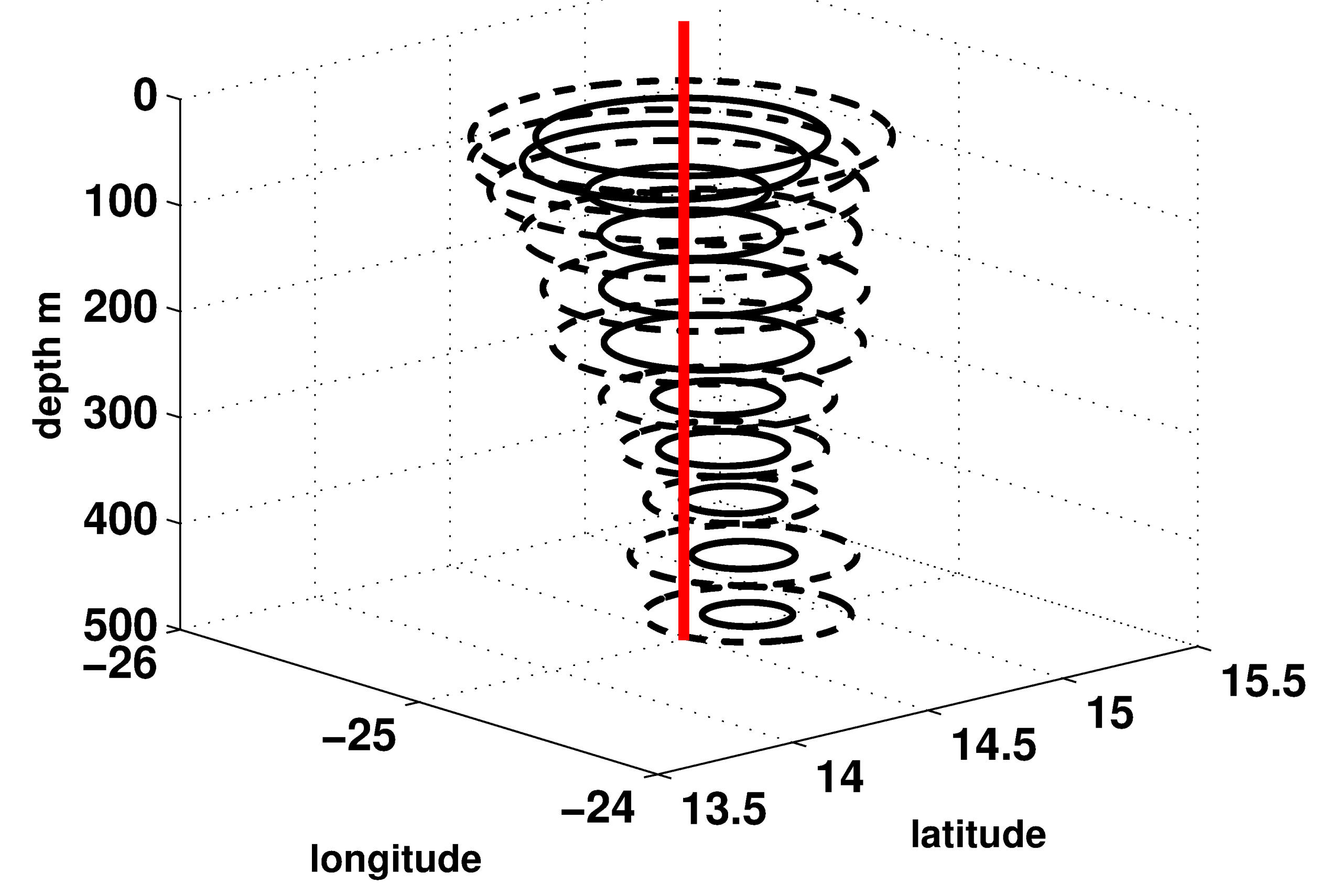
circle of linear velocity profile
, circle of positive vorticity




\section{REEBUS field campaigns}

\section{About REEBUS}

Oceanic eddies affect the physical, biogeochemical and biological properties of coastal upwelling areas. It is hypothesized that climate change will alter the characteristics and statistics of oceanic eddies with probably profound effects on the dynamics and functions of coastal upwelling systems. REEBUS performs a multi-facetted, multi-component field study on the role of the different types of eddies for the lateral transport of bio- geochemical properties and its coupling to the carbon pump in the Canary Current System, one of the most productive Eastern Boundary Upwelling Systems. www.ebus-climate-change.de/reebus
Field campaigns. The eddies that were promising, strong enough, and reachable during the campaign times happened to be cyclonic eddies. They were intensely sampled from ship and various autonomous platforms.
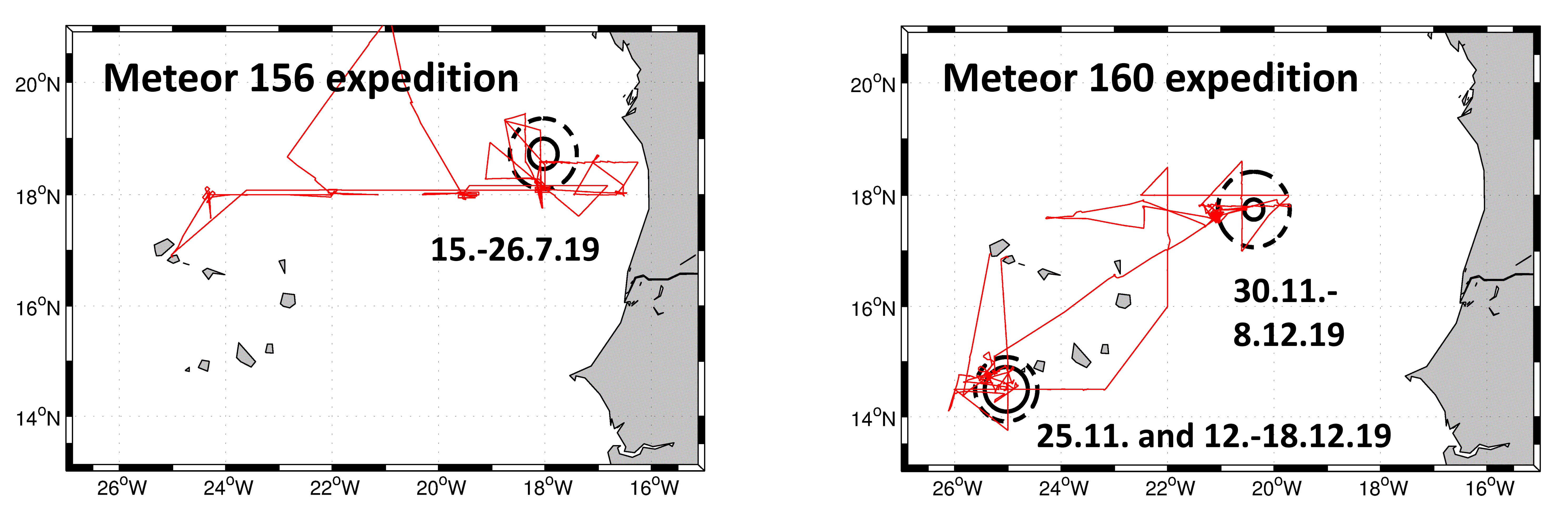

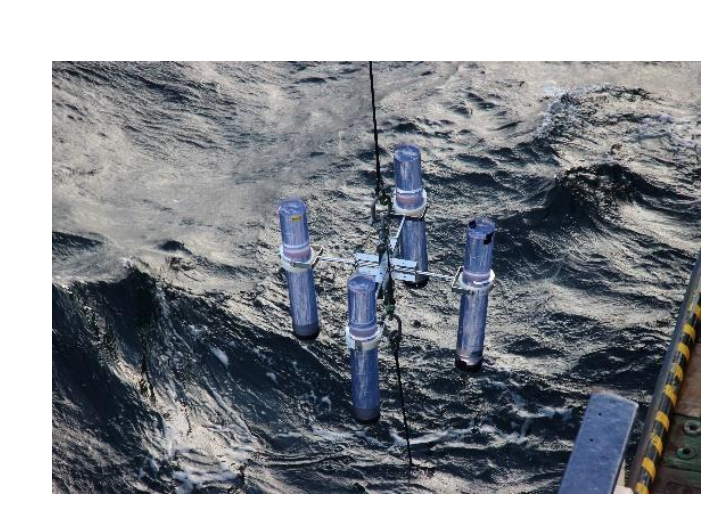

Sediment trap

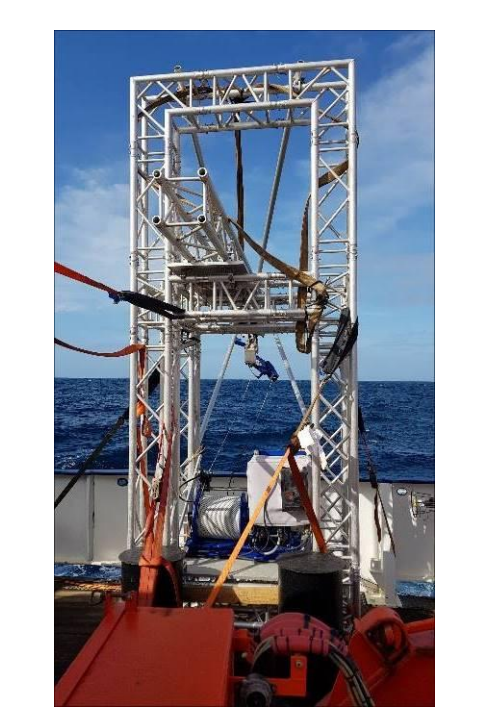

Moving Vessel Profiler

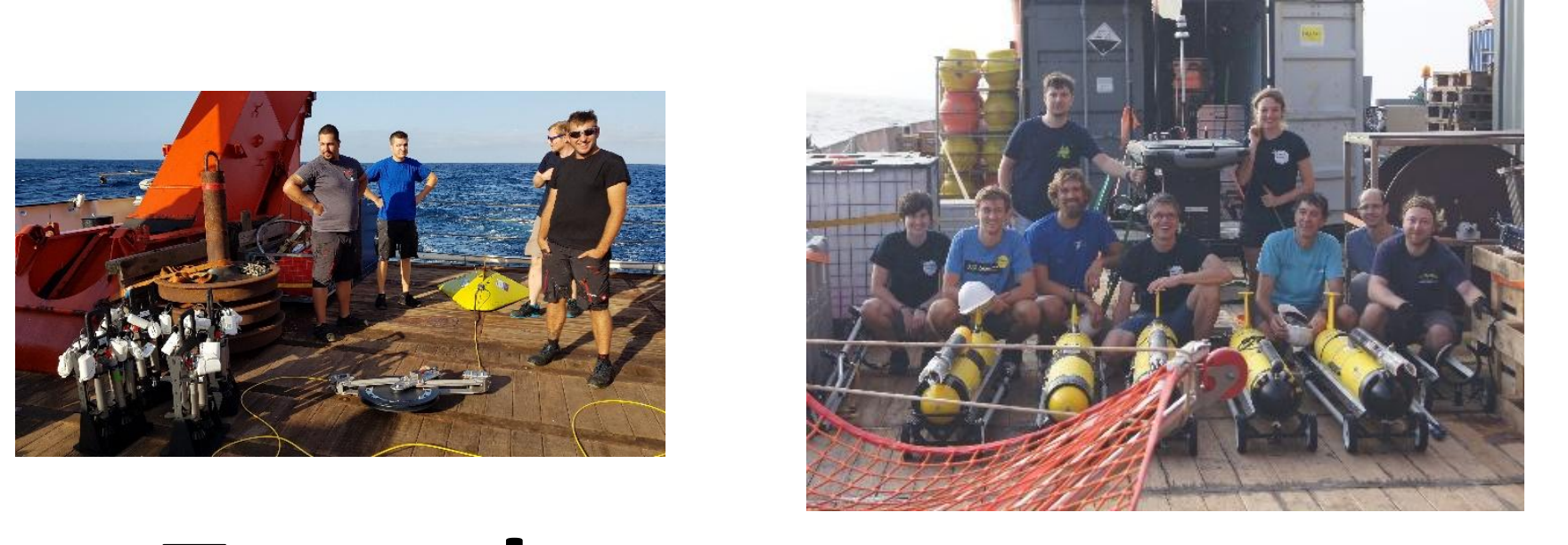

Towed Array
Ocean Glider

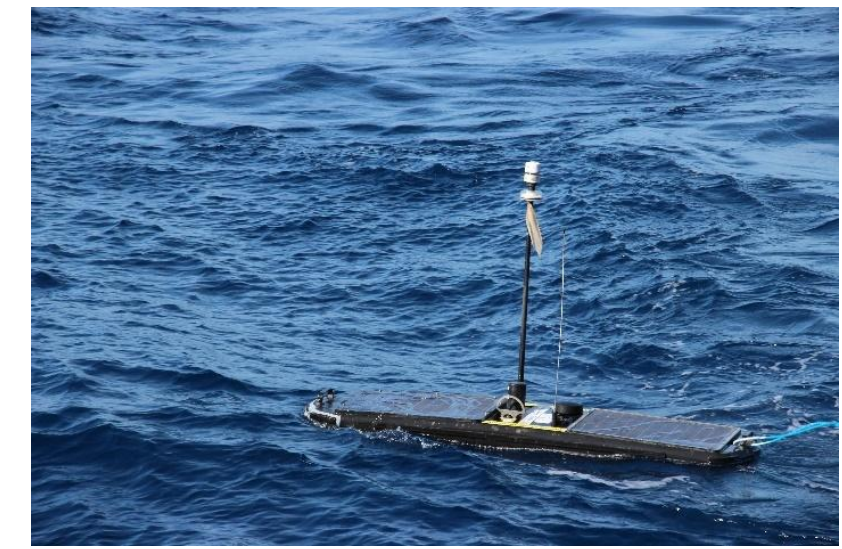

Waveglider

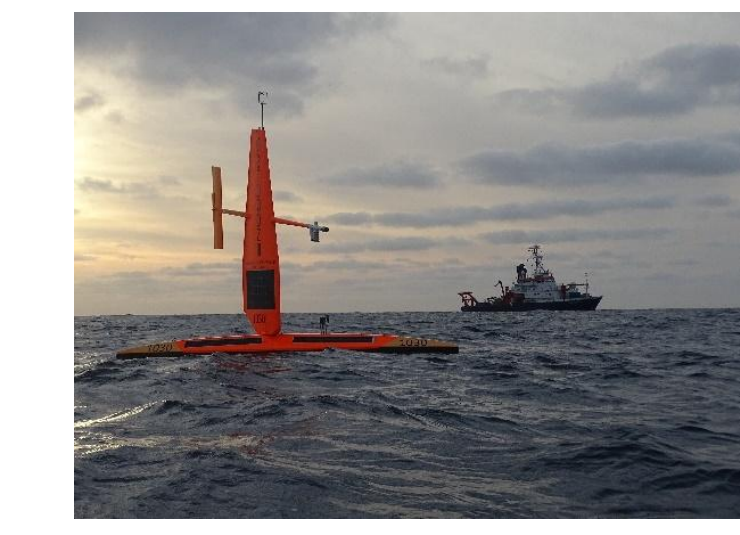

Saildrone

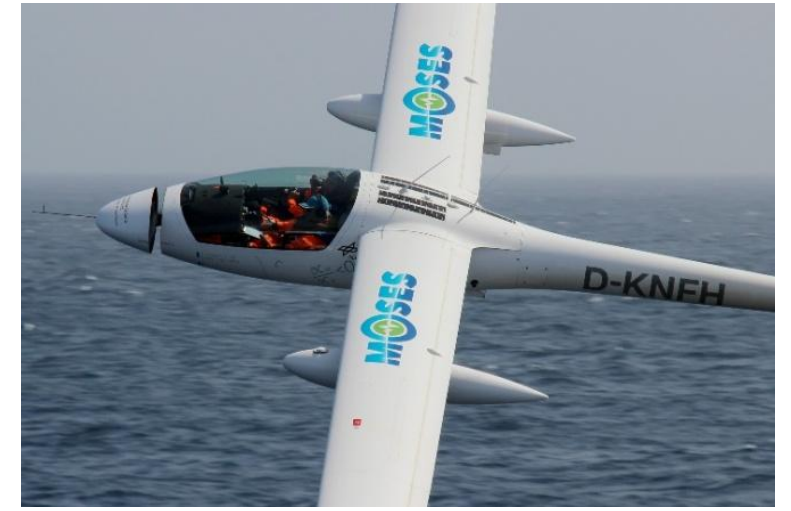

Sailplane 'Stemme' 


\section{Current velocities - locate and characterize eddies}

Satellite data are an orientation but often not satisfying to locate eddies for dedicated biogeochemical sampling.

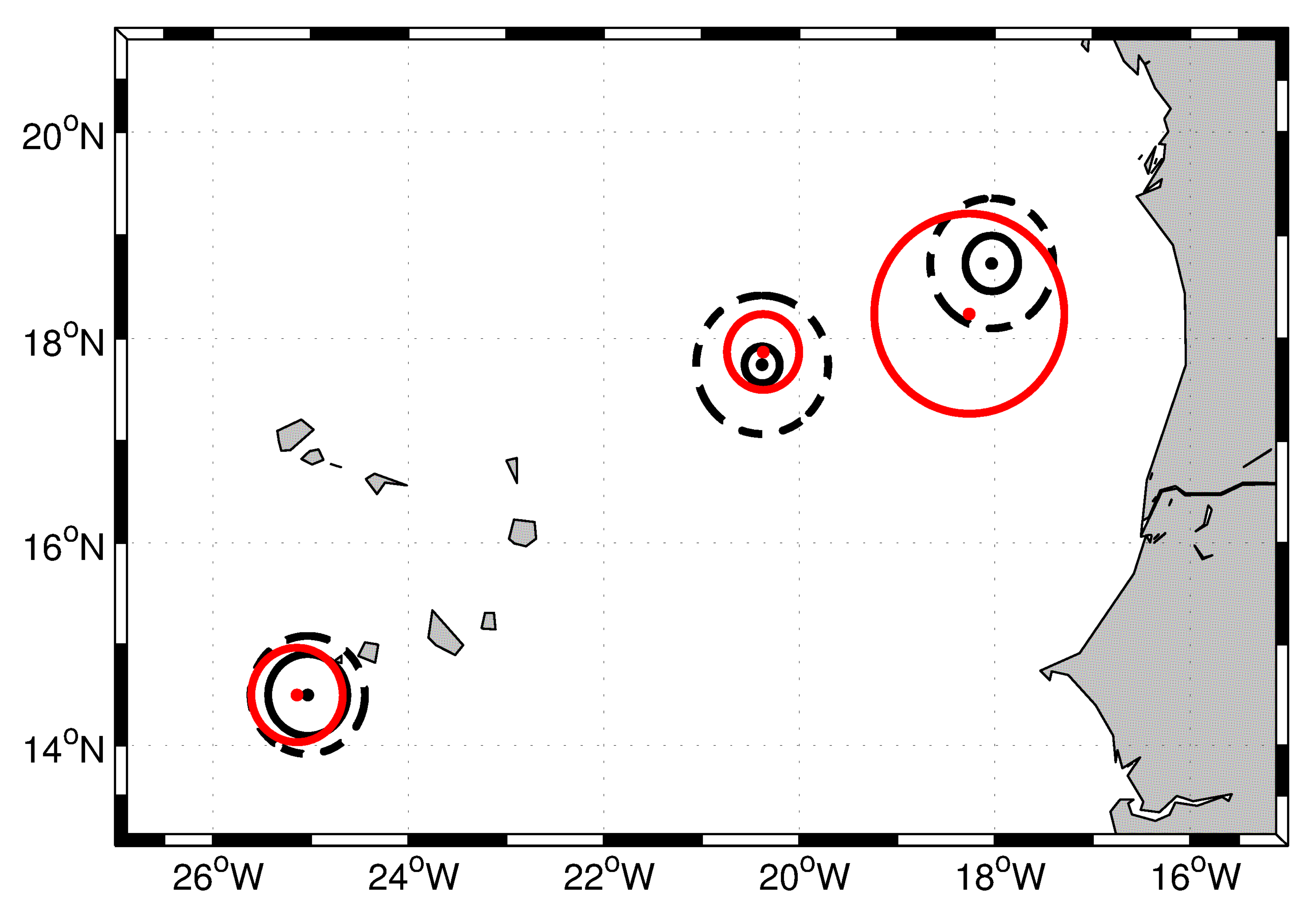

vmADCP-derived eddy-characterizing radii (black) vs. AMEDA radii of maximum azimutal velocity (red) Adapted from Andrae 2020

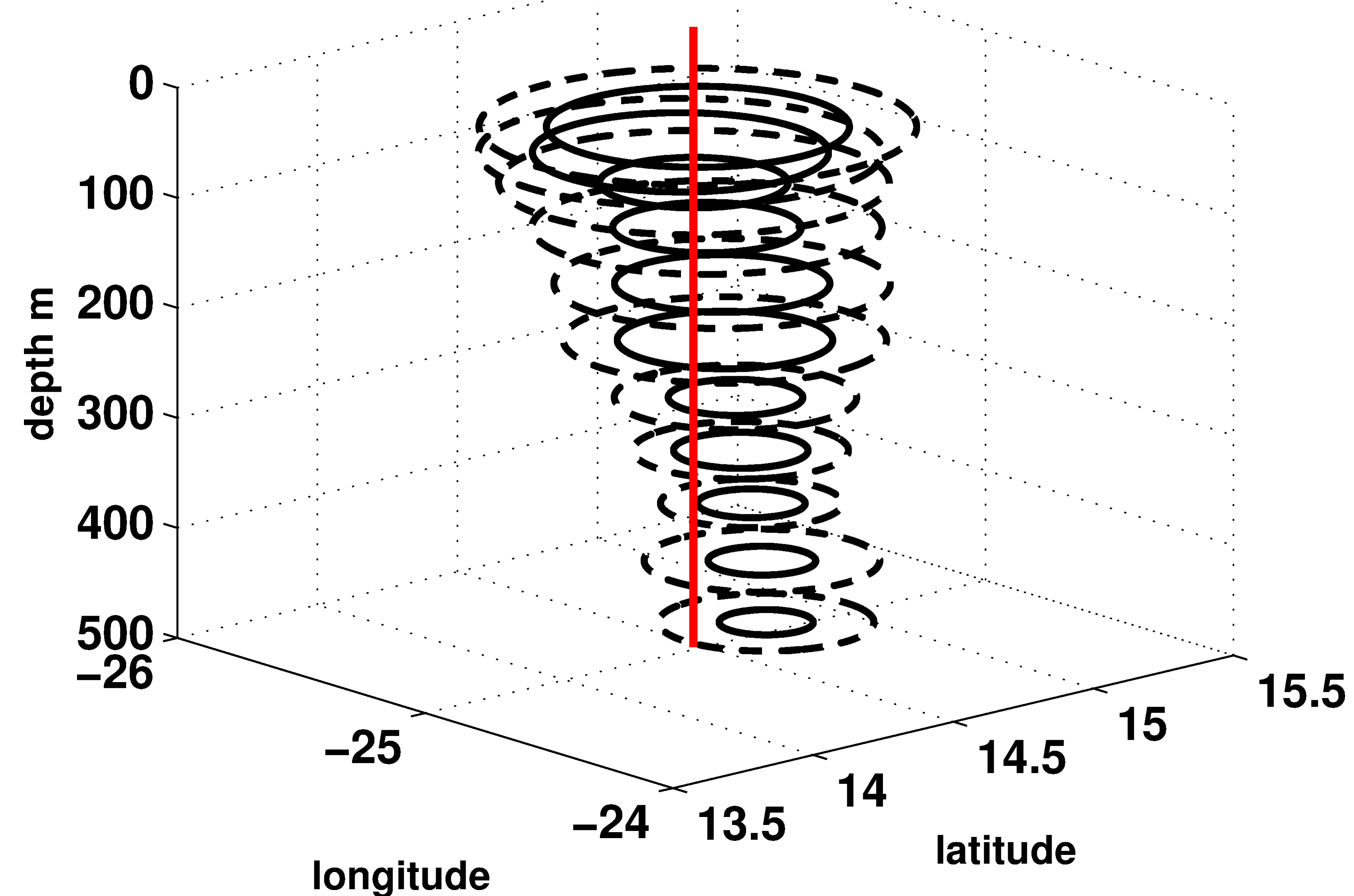

Vertical structure of the eddy at $25 \mathrm{~W} 14.5 \mathrm{~N}$. The surface rotation centre position hardly hits the eddy limits in the deeper parts. 


\section{Current velocities - locate and characterize eddies}

\section{Multi-section ship ADCP data as a base to locate and limit eddy structure in 3-D}
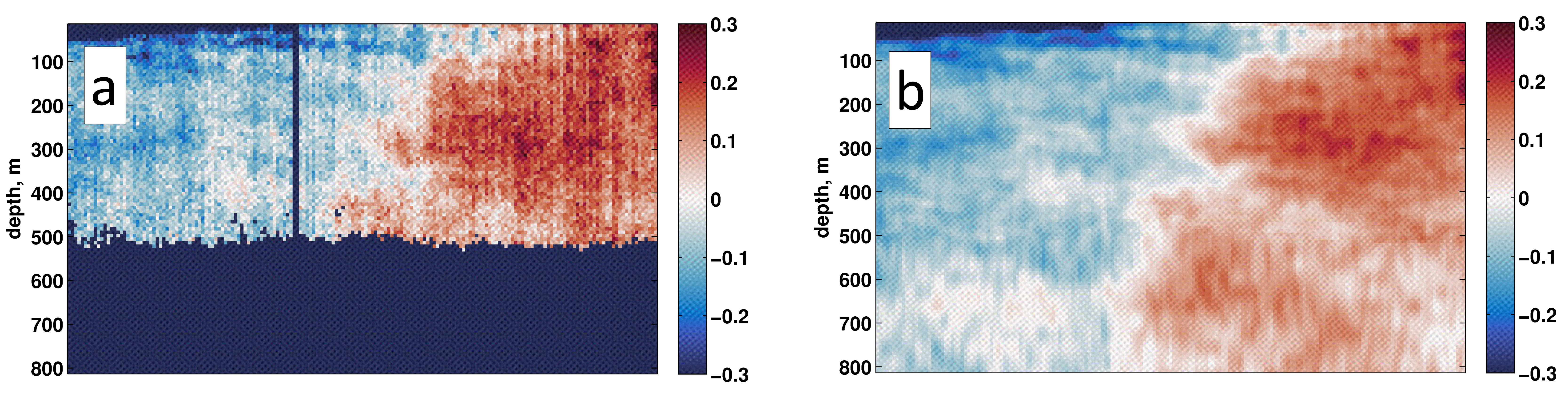

Data preparation beyond standard ADCP

postprocessing:

$75 \mathrm{kHz}$ vmADCP calibrated 1-minute-averaged data (a) are further merged with $38 \mathrm{kHz}$ vmADCP data, filtered to reduce white noise, and detided (b)
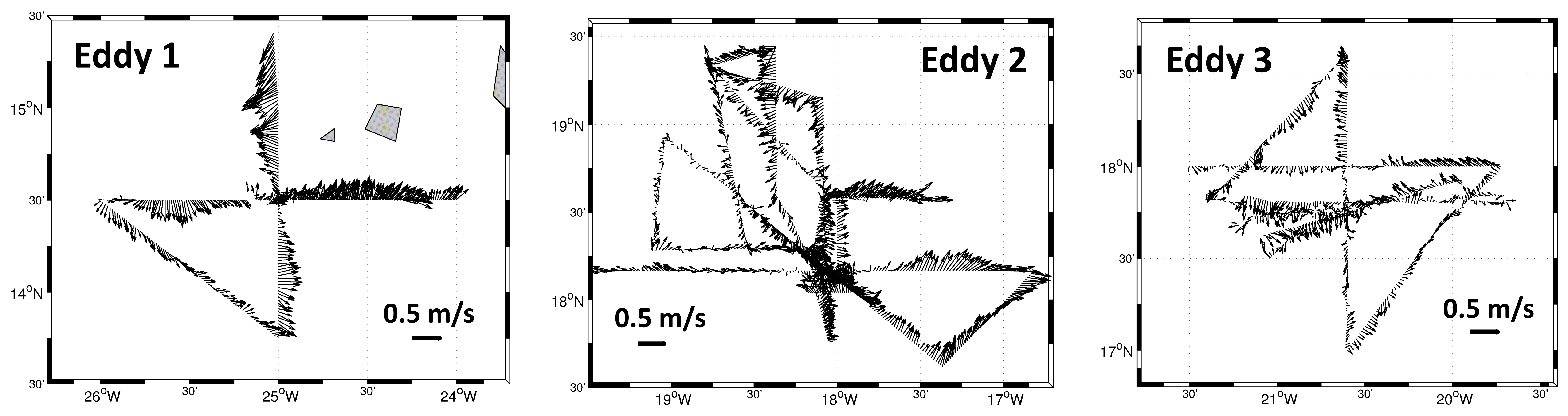

Different eddies are visually identifiable and locatable with different ease

(Averaged velocity at $15 \mathrm{~m}$ to $45 \mathrm{~m}$ depth, corresponding to mixed layer) 


\section{Current velocities - locate and characterize eddies}

Azimutal and radial velocity component

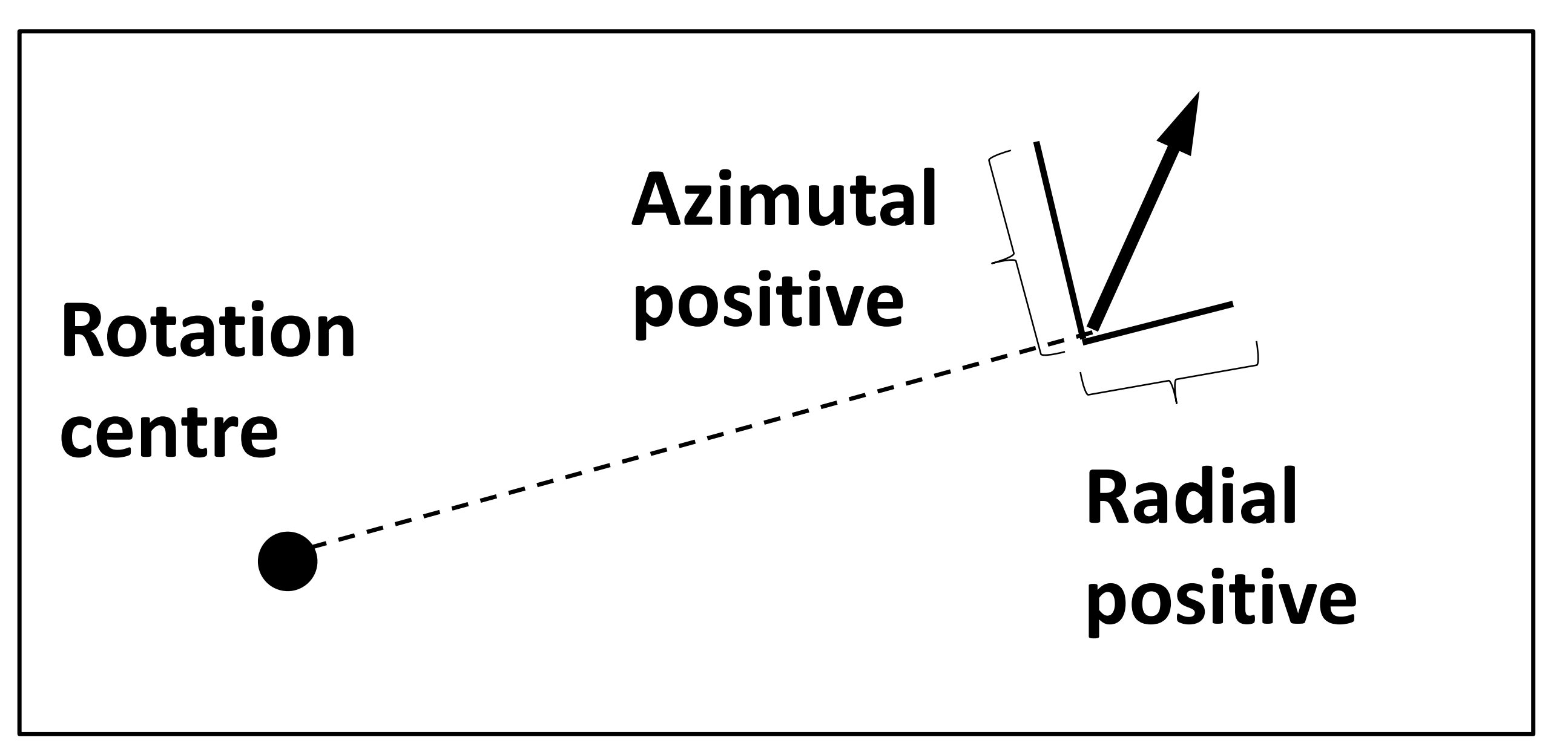

Fixing a rotation centre, velocities are binned by radius

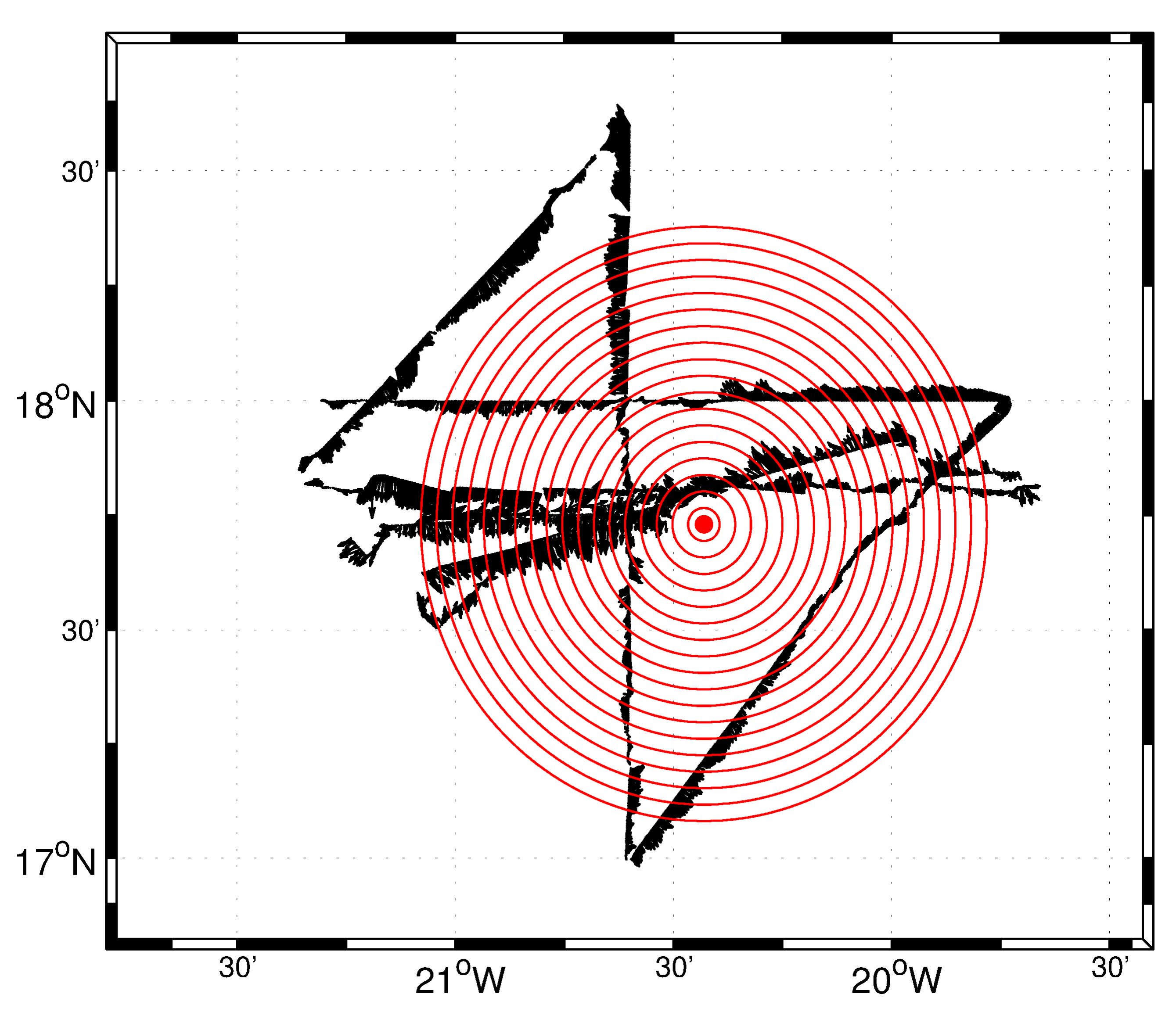

\section{Search procedure for optimum rotation centre}

\section{Assumptions:}

Axisymmetric velocity profile (circular eddy shape) expected ADCP sampling assumed representative

(Some prejudices on smoothness and possible shape of velocity profiles)

For each horizontal layer:

Determine optimum rotation centre from

- Minimization of radial velocity component

(Bendinger 2020, based on work of Castelao and Johns 2011)

- Side conditions are: azimutal velocity profile of reasonable shape and low variance

Binned azimutal velocity vs. radius

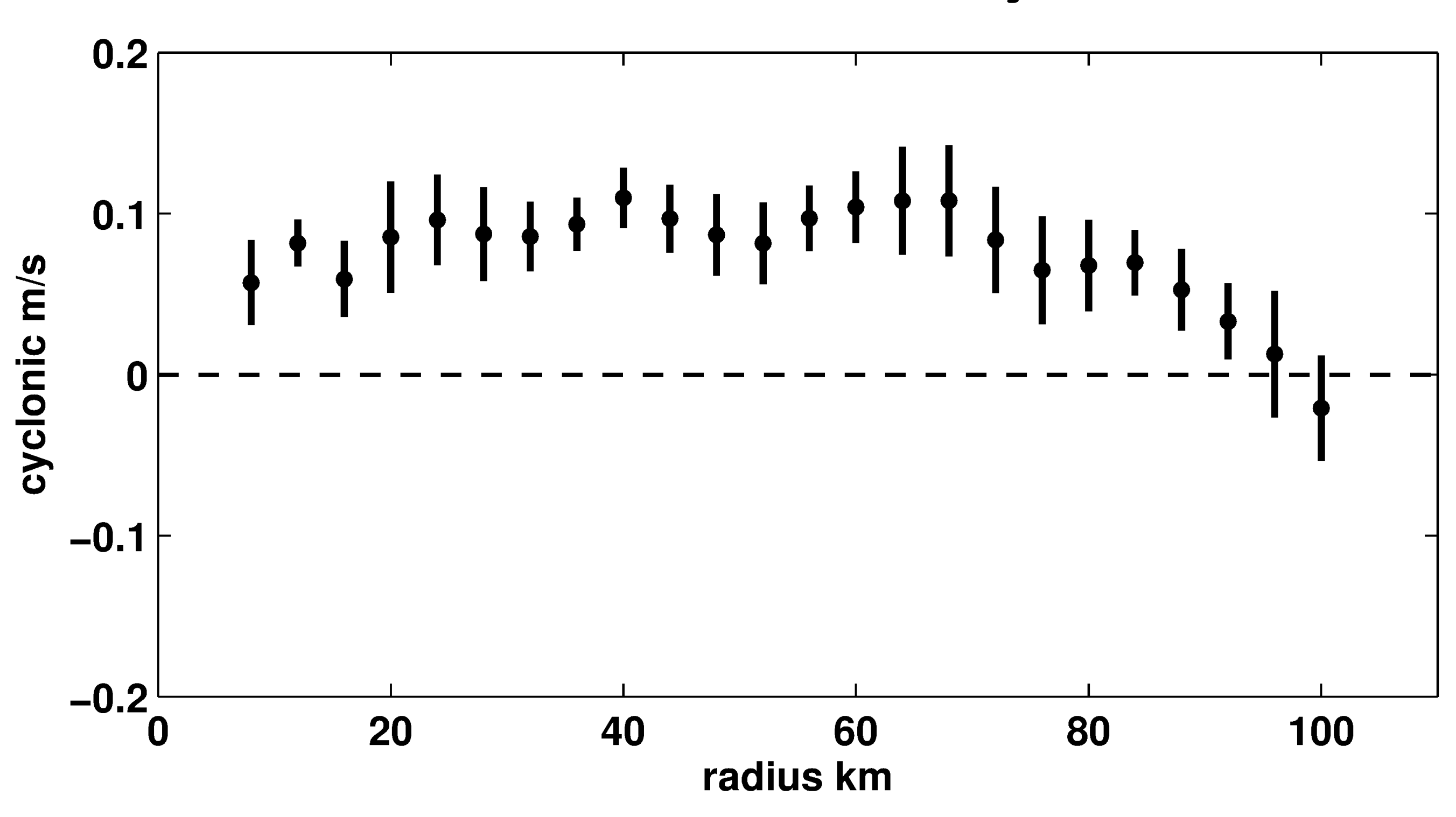

Unrealistic shape (after applying an unrealistic background drift of $7 \mathrm{~cm} / \mathrm{s}$ to $S W$ )

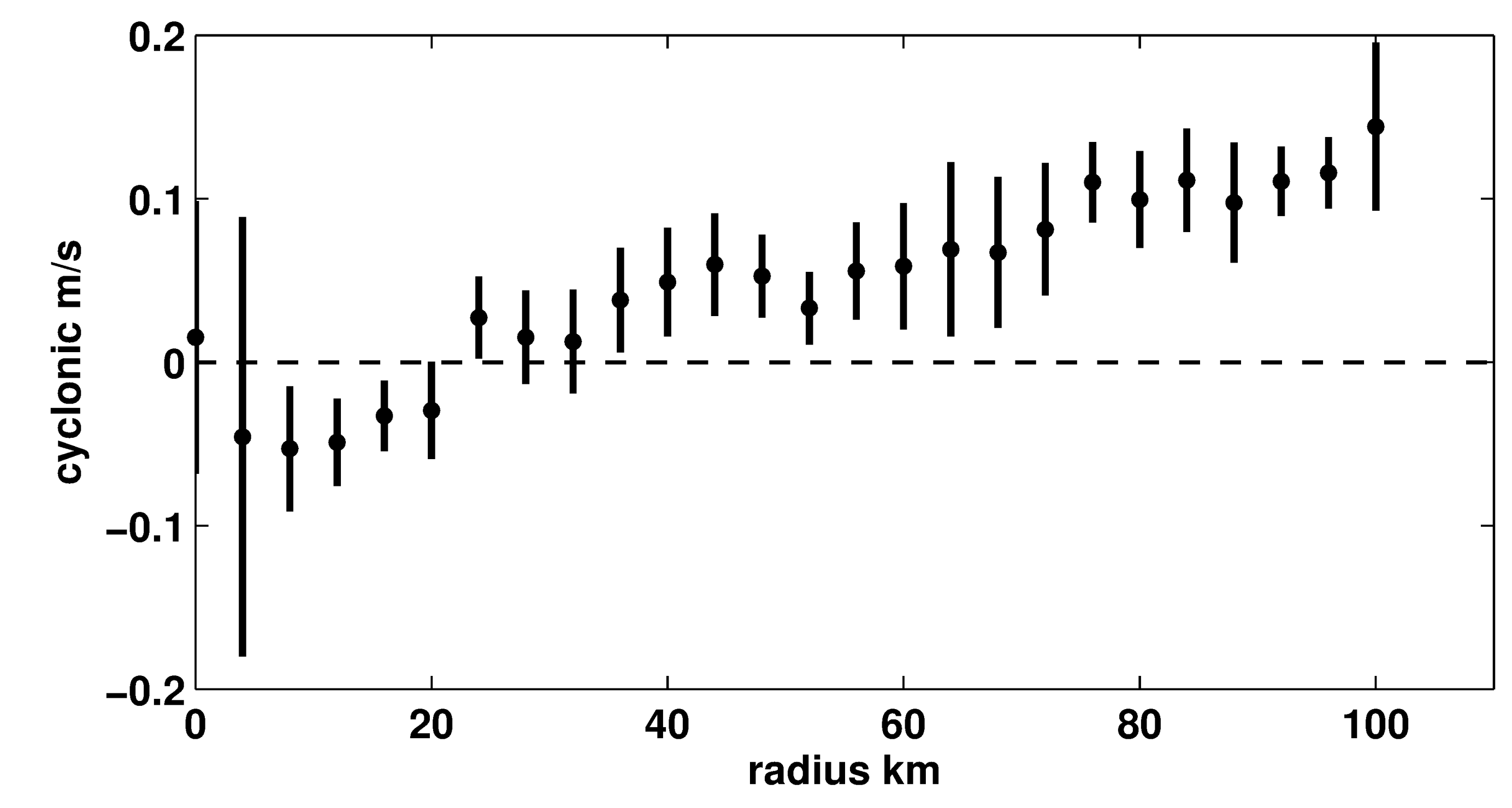




\section{Current velocities - locate and characterize eddies}
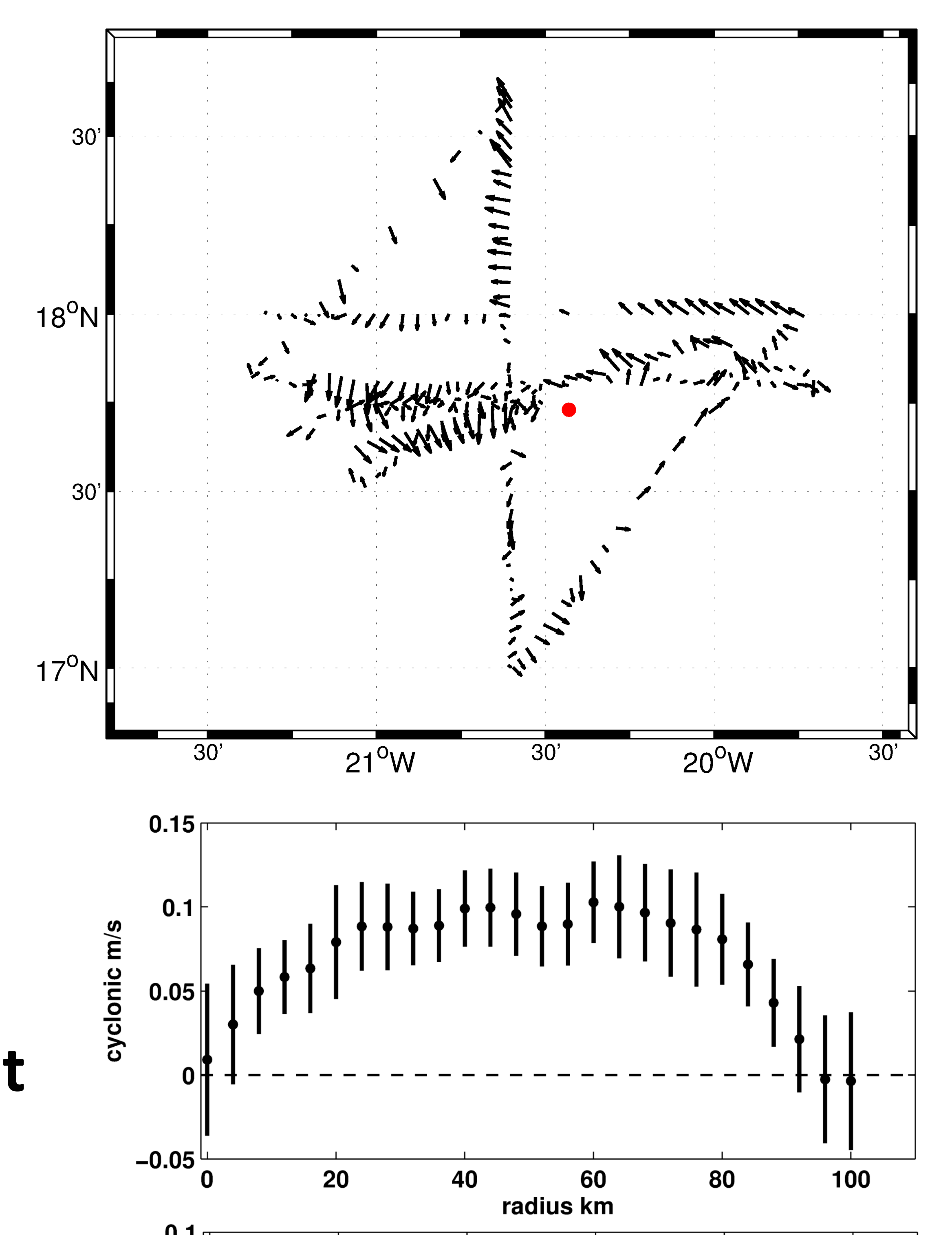

Radial component

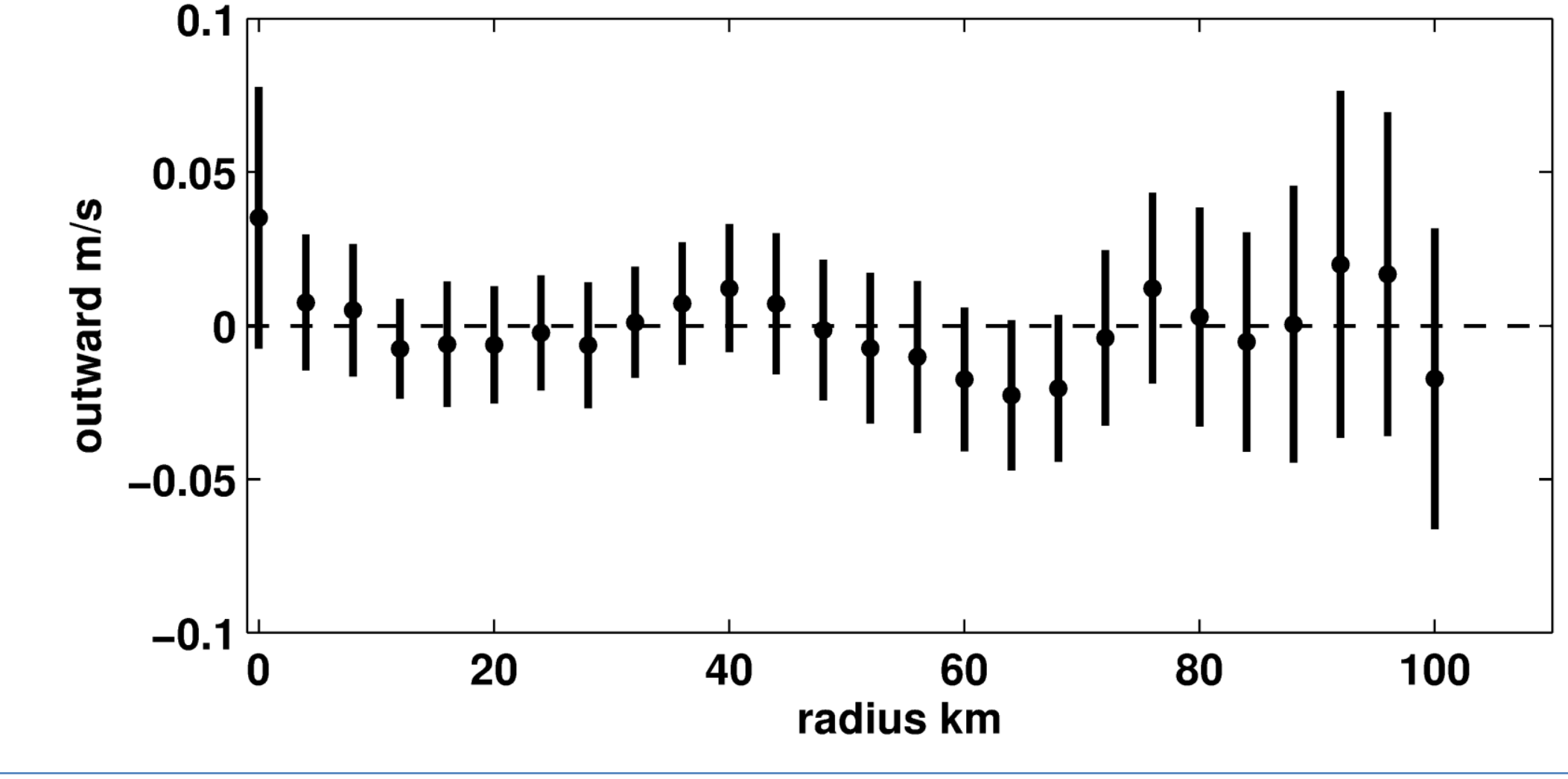

\section{Assumed axisymmetric structure}
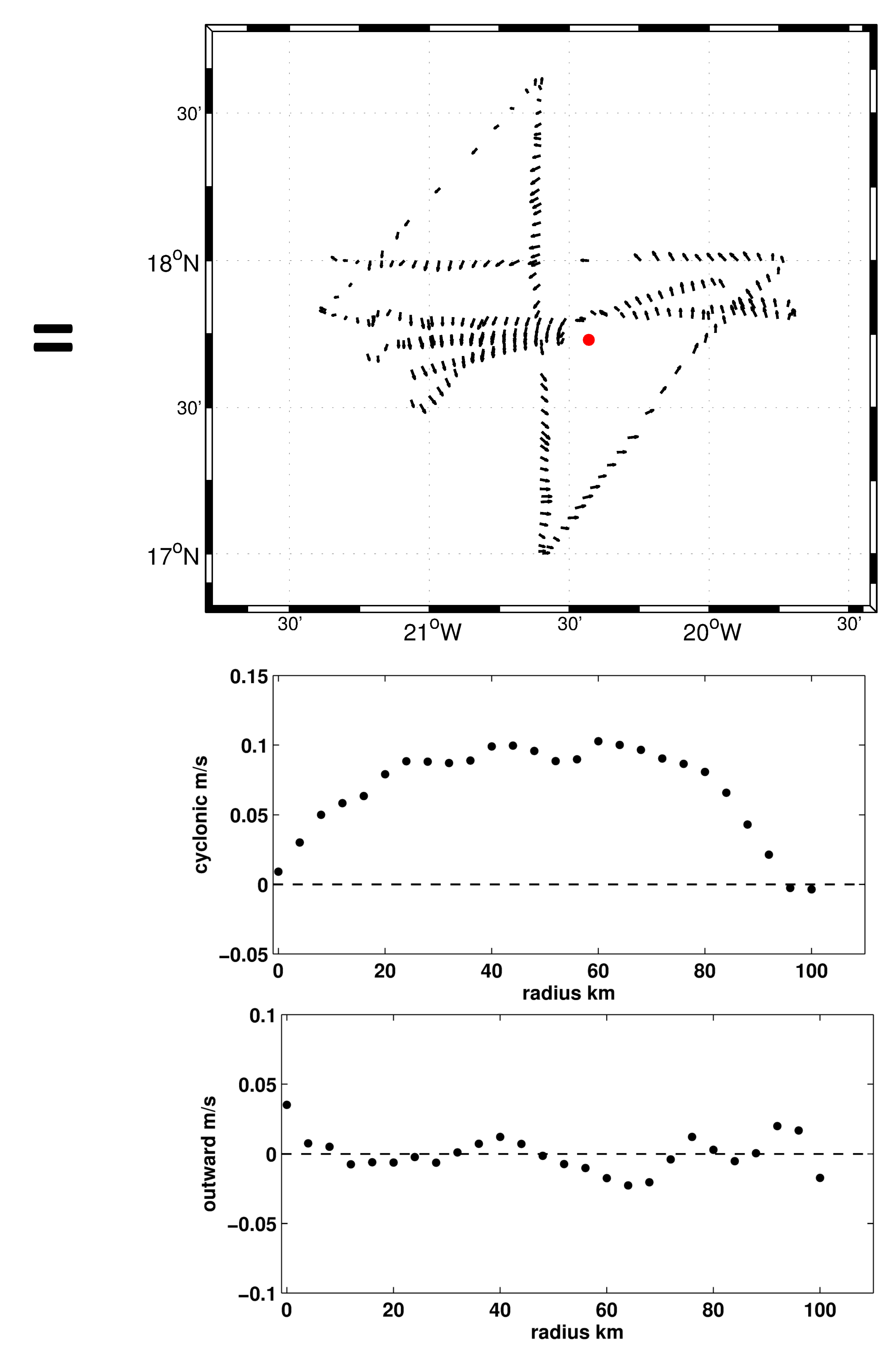

\section{Residual}
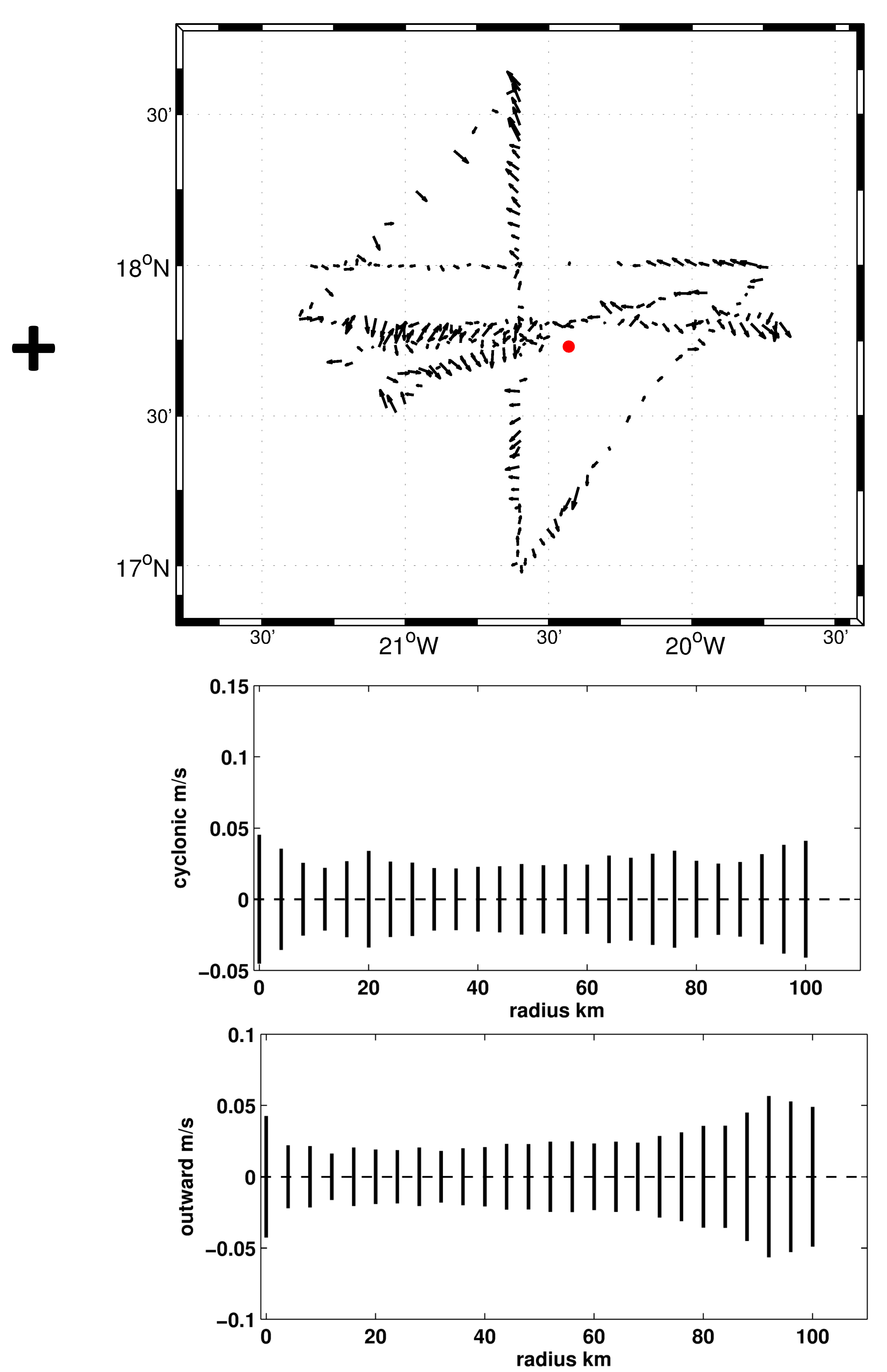


\section{Current velocities - locate and characterize eddies}

\section{Assumed axisymmetric structure}

Vorticity for

axisymmetric case:

$\zeta=d u_{a z} / d r+u_{a z} / r$

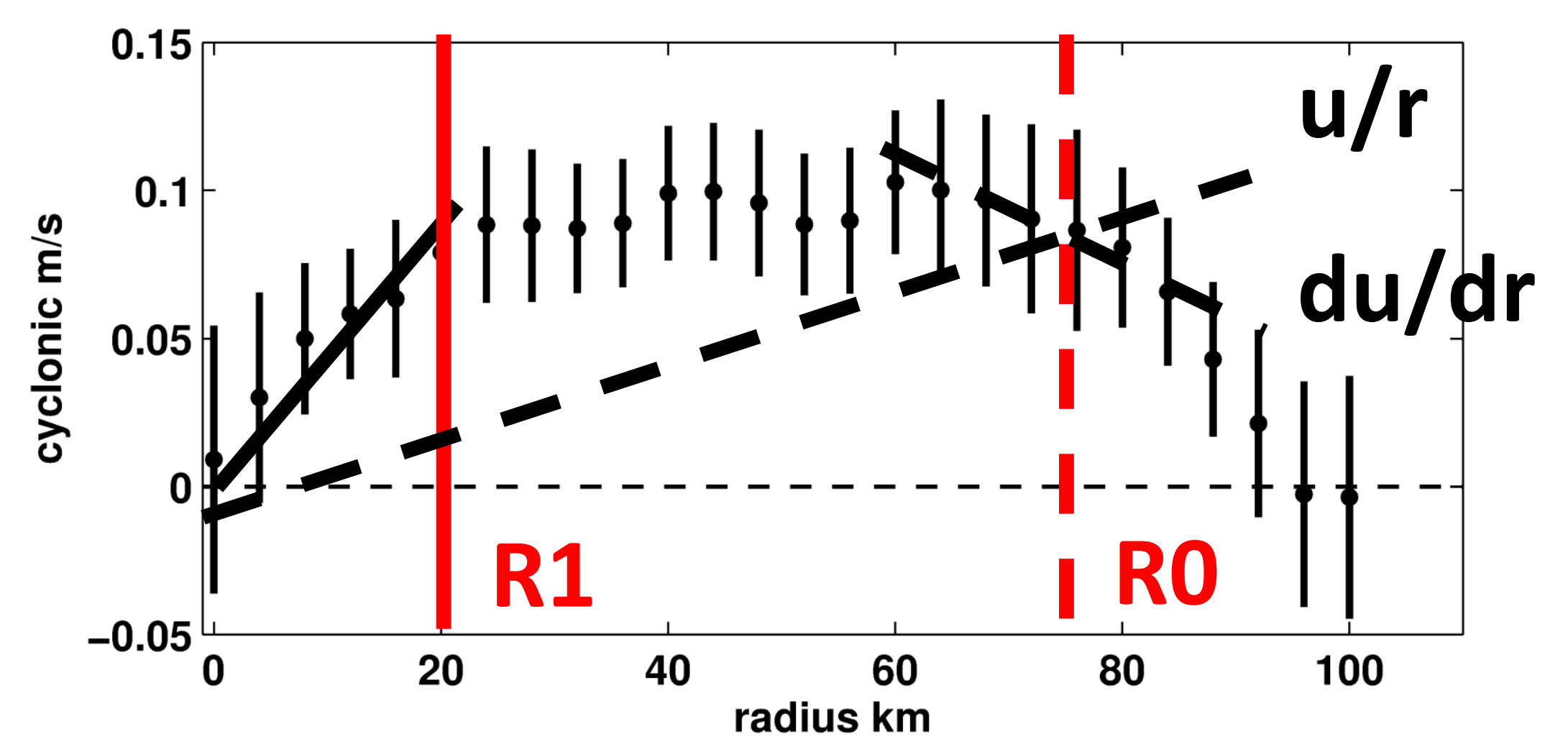

Divergence for axisymmetric case:

$\operatorname{div}=d u_{r a d} / d r+u_{r a d} / r$

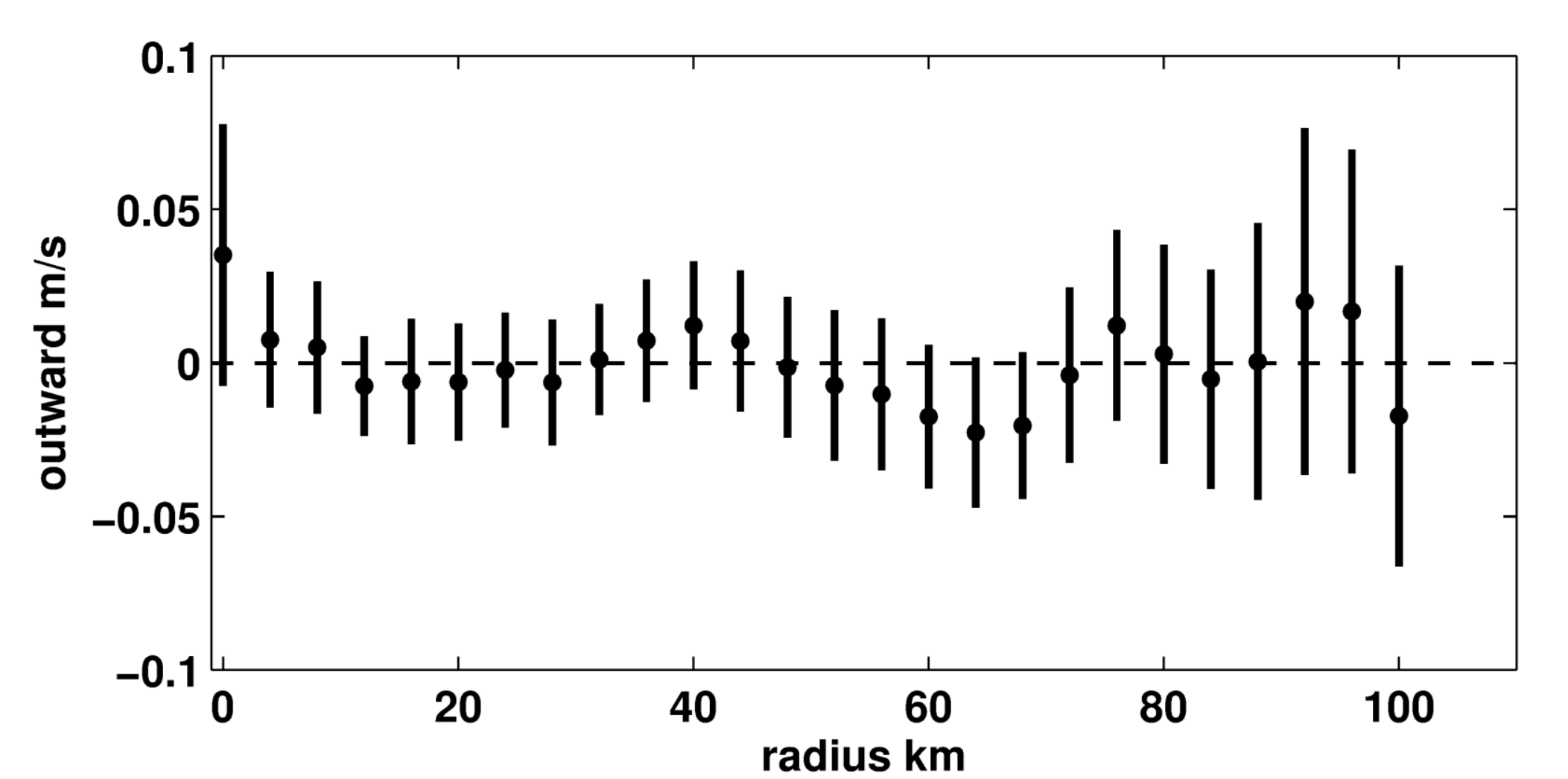

Estimate 2 radii:

R1 where linear profile can be fitted

RO where vorticity $=0$,

i.e. $d u / d r=-u / r$

There may be some structure in the divergence inside RO, but none of the single values is significant.

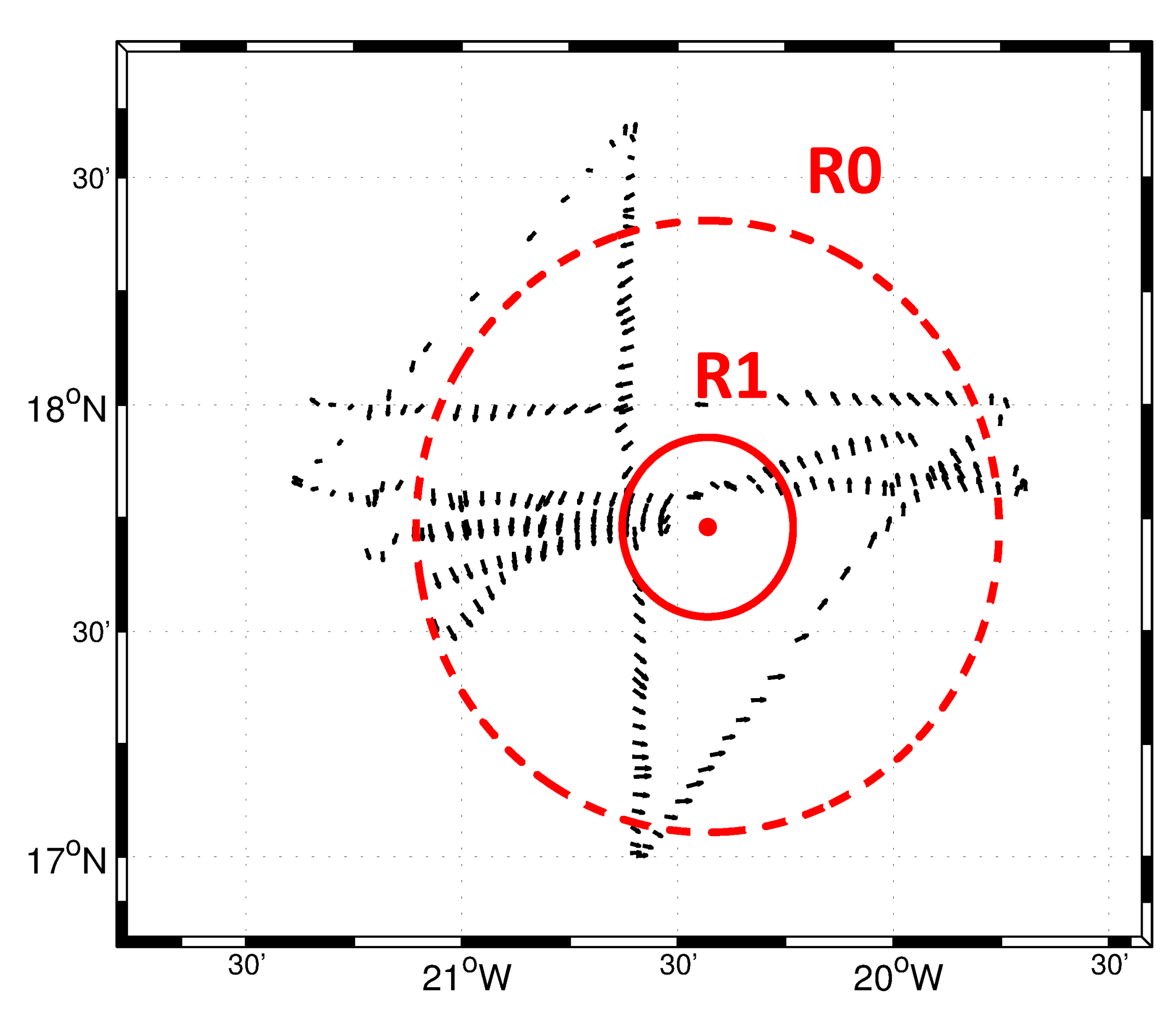

Mean drift of eddies is an issue Ignoring an existing mean drift can sensitively change results, produce artefacts in derived velocity profiles, particularly near the rotation centre.

But drift can also be estimated as part of the optimum search procedure.

In the end the localization procedure delivers estimates of a rotation centre, $\mathbf{2}$ radii, and a drift velocity for each horizontal layer. Plus estimates of vorticity and divergence fields. 


\section{Example - weakest eddy 3, mixed layer (15m to $45 \mathrm{~m})$}

\section{Variation of assumed drift}

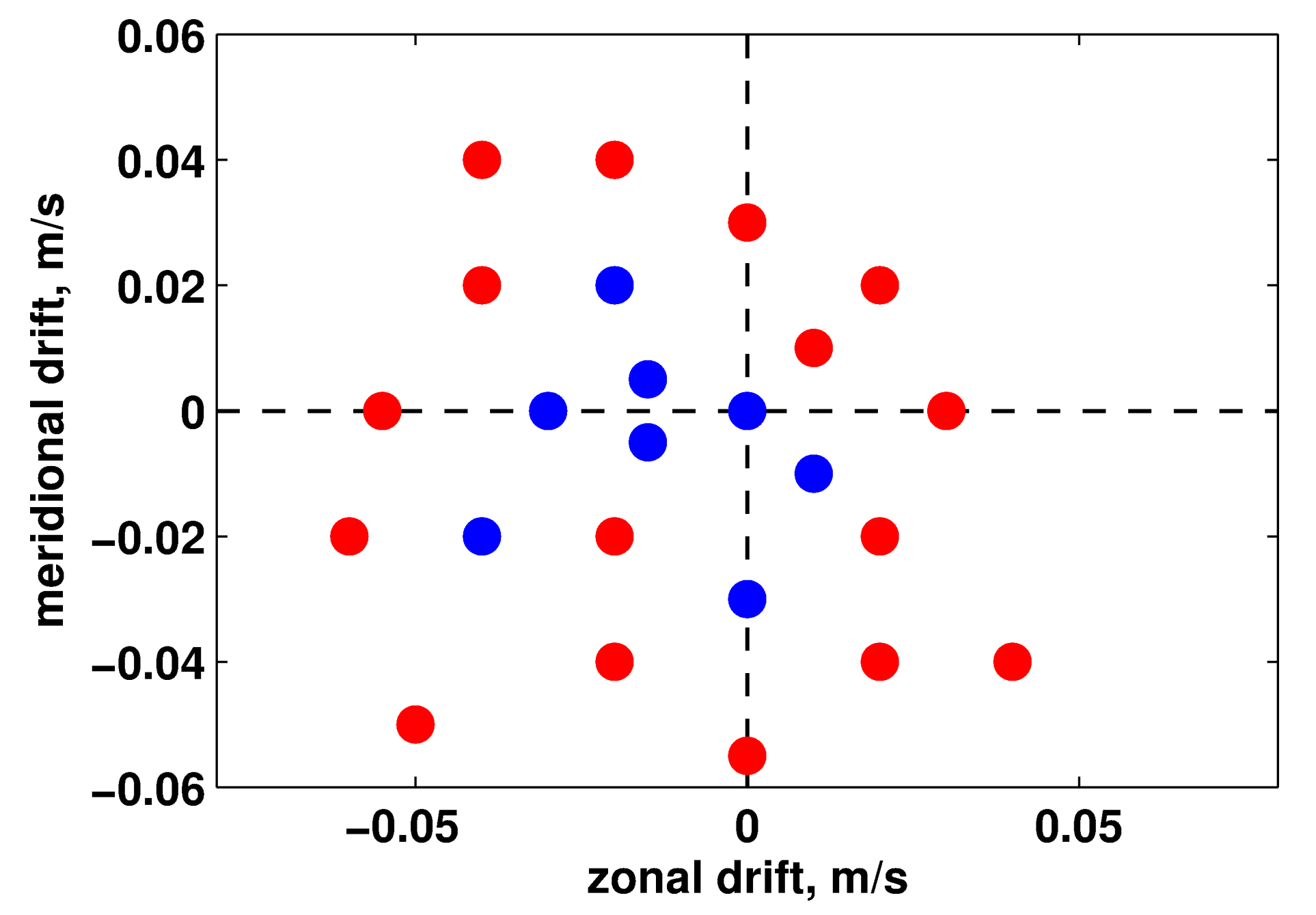

Blue dots: solutions with reasonable azimutal structure.

Drift average: $1.5 \mathrm{~cm} / \mathrm{s}$ to WSW
Corresponding centres

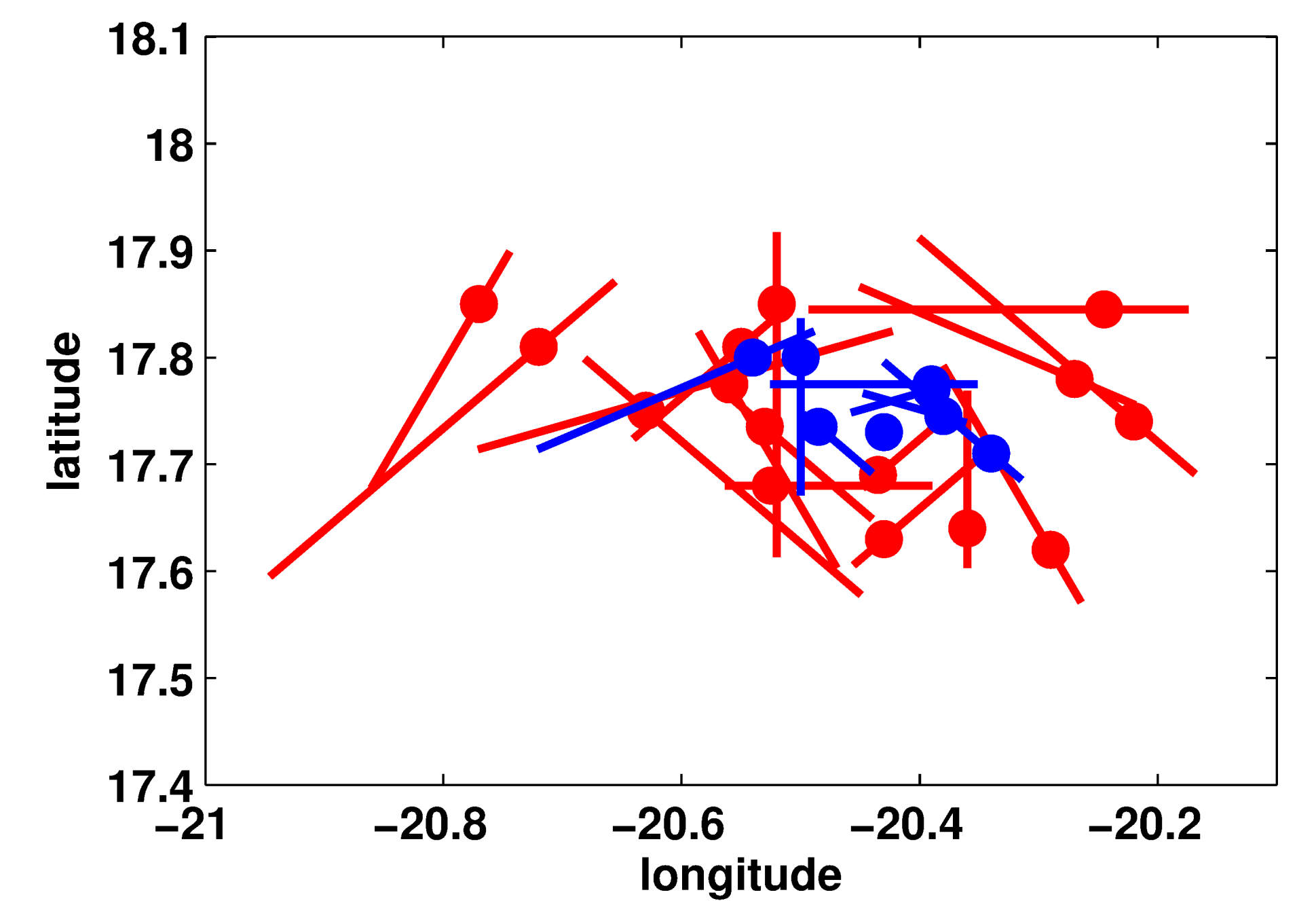

Dots: estimated positions of rotation centre on 30.11.19, Lines:during 29.11.-6.12.19

Mean vorticity/divergence profiles (from 8 reasonable azimutal cases)

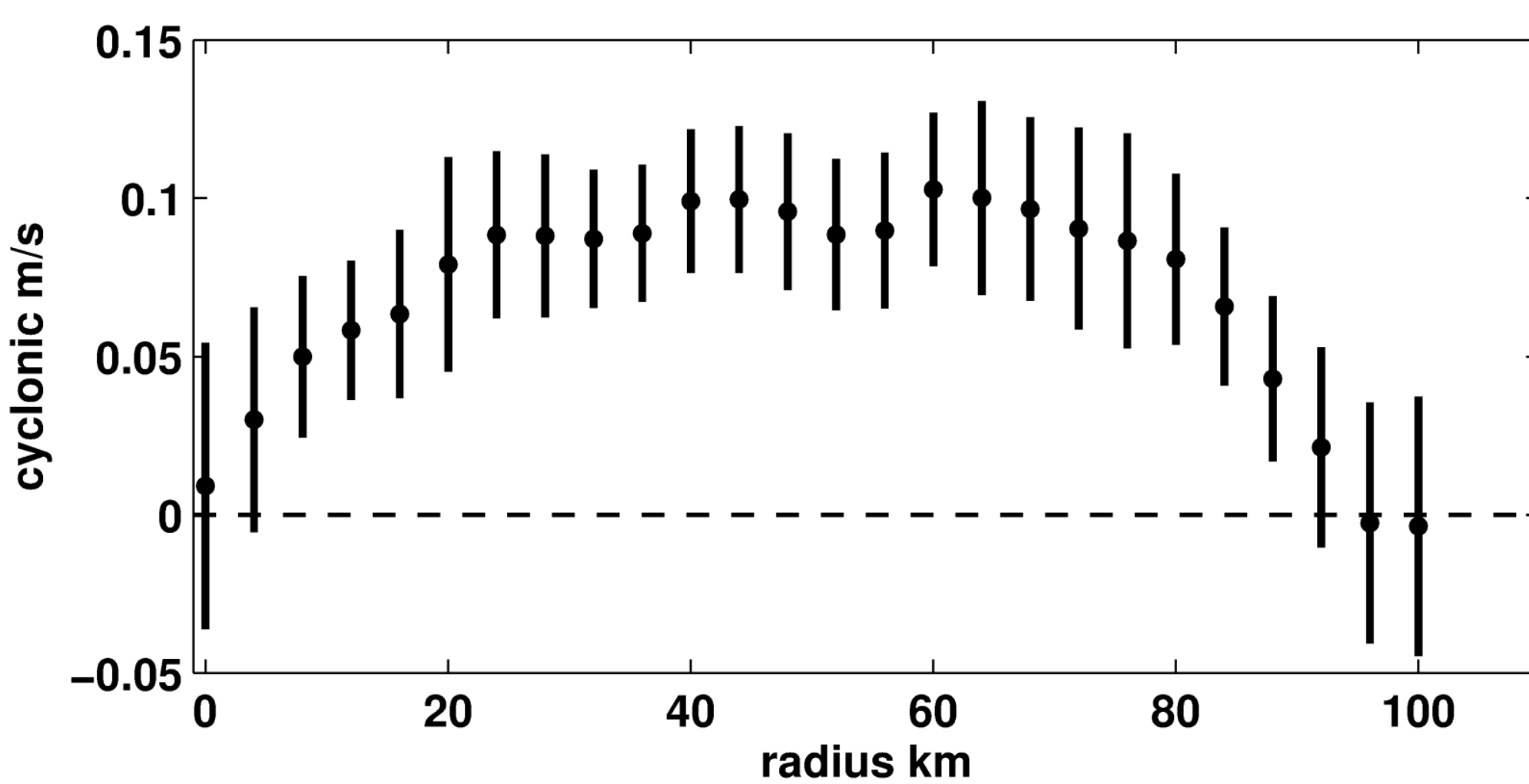

$\mathrm{R} 1=20 \mathrm{~km} \quad \mathrm{R} 0=75 \mathrm{~km}$ Centre vorticity $=0.2 * f$

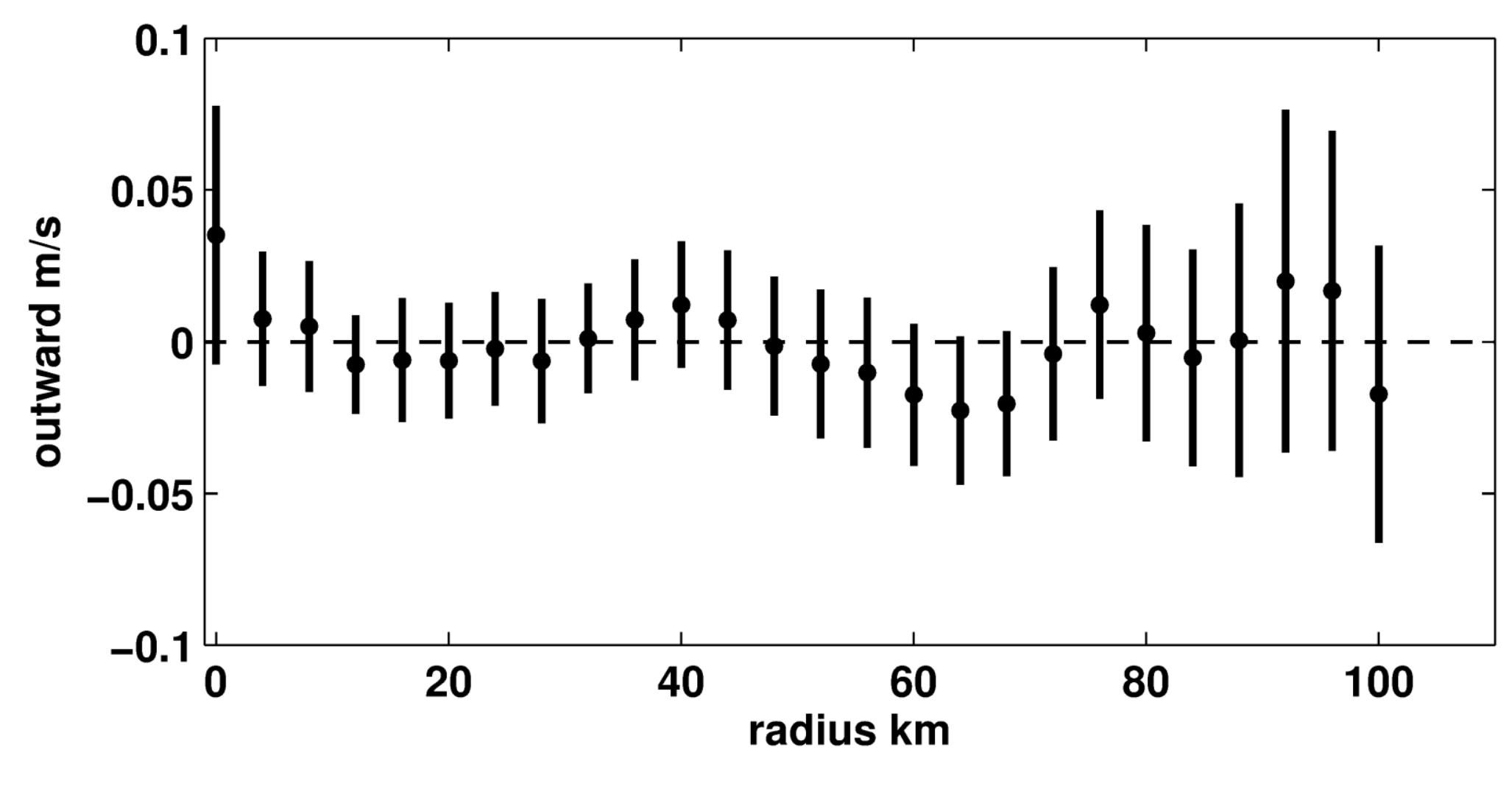

Limit estimate of vertical velocity at MLD: $\mathrm{w}<10 \mathrm{~m} / \mathrm{d}$
SST structure

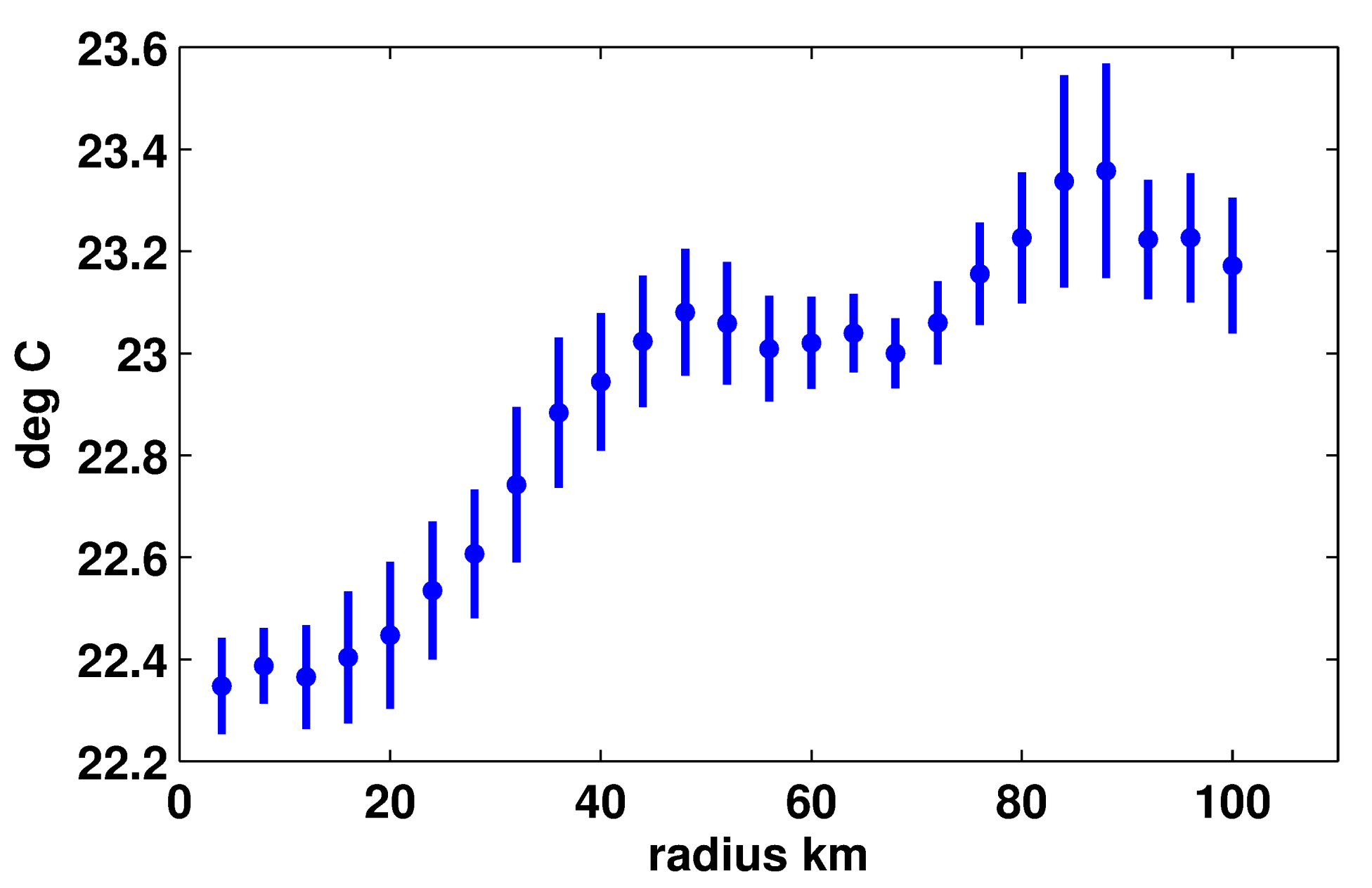

SSS structure

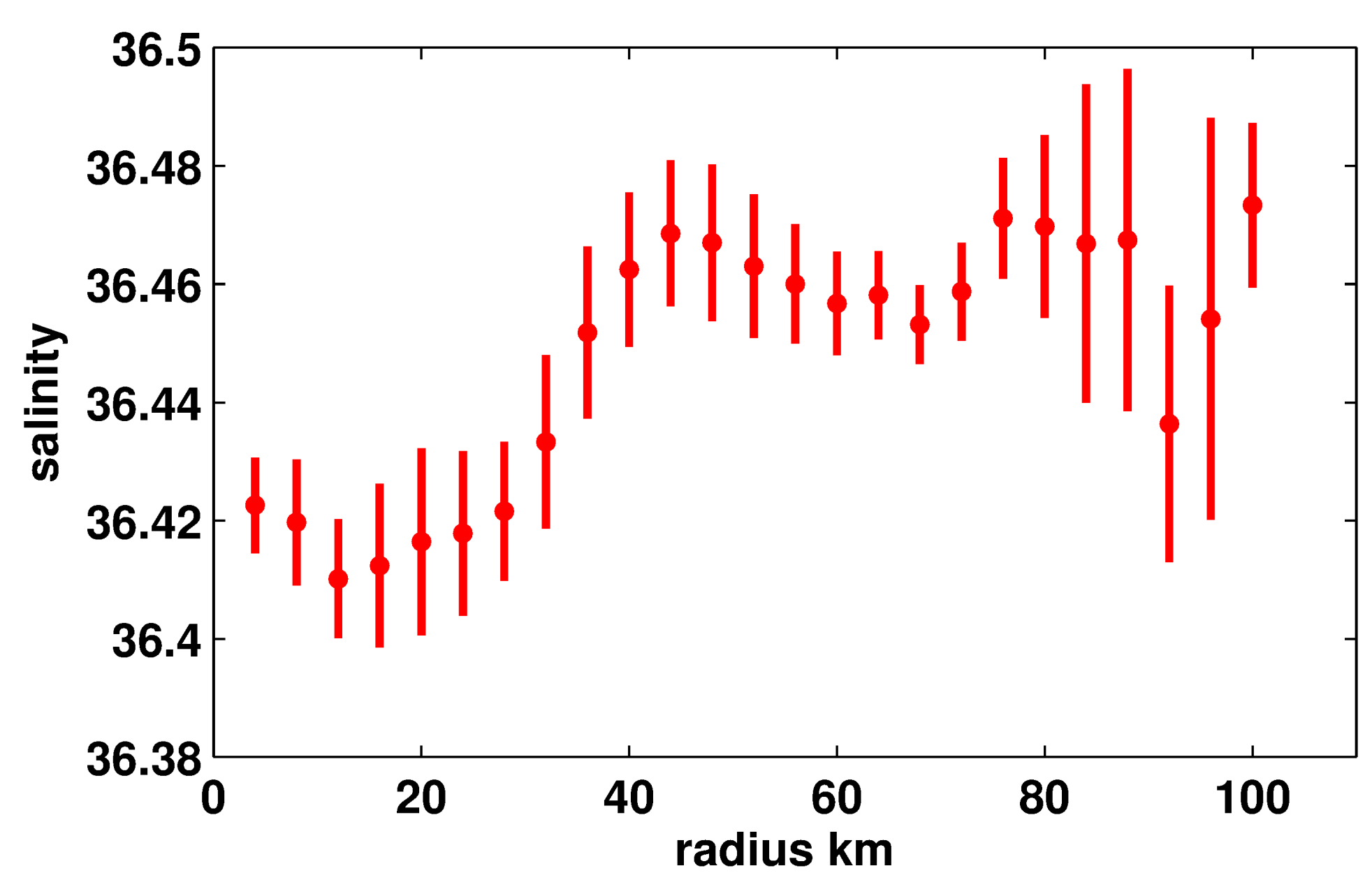

MLD structure

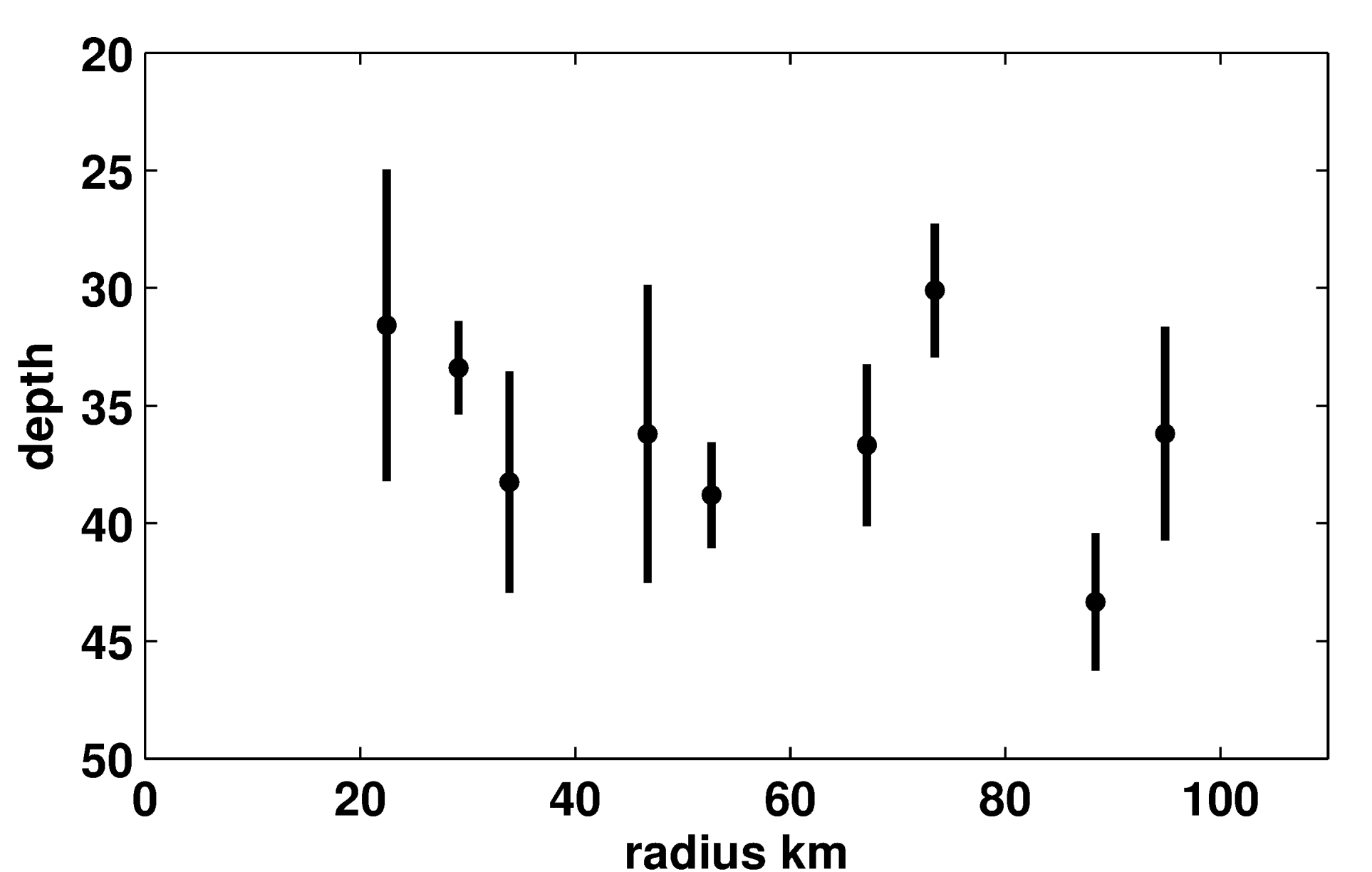

Flu max rel. to MLD

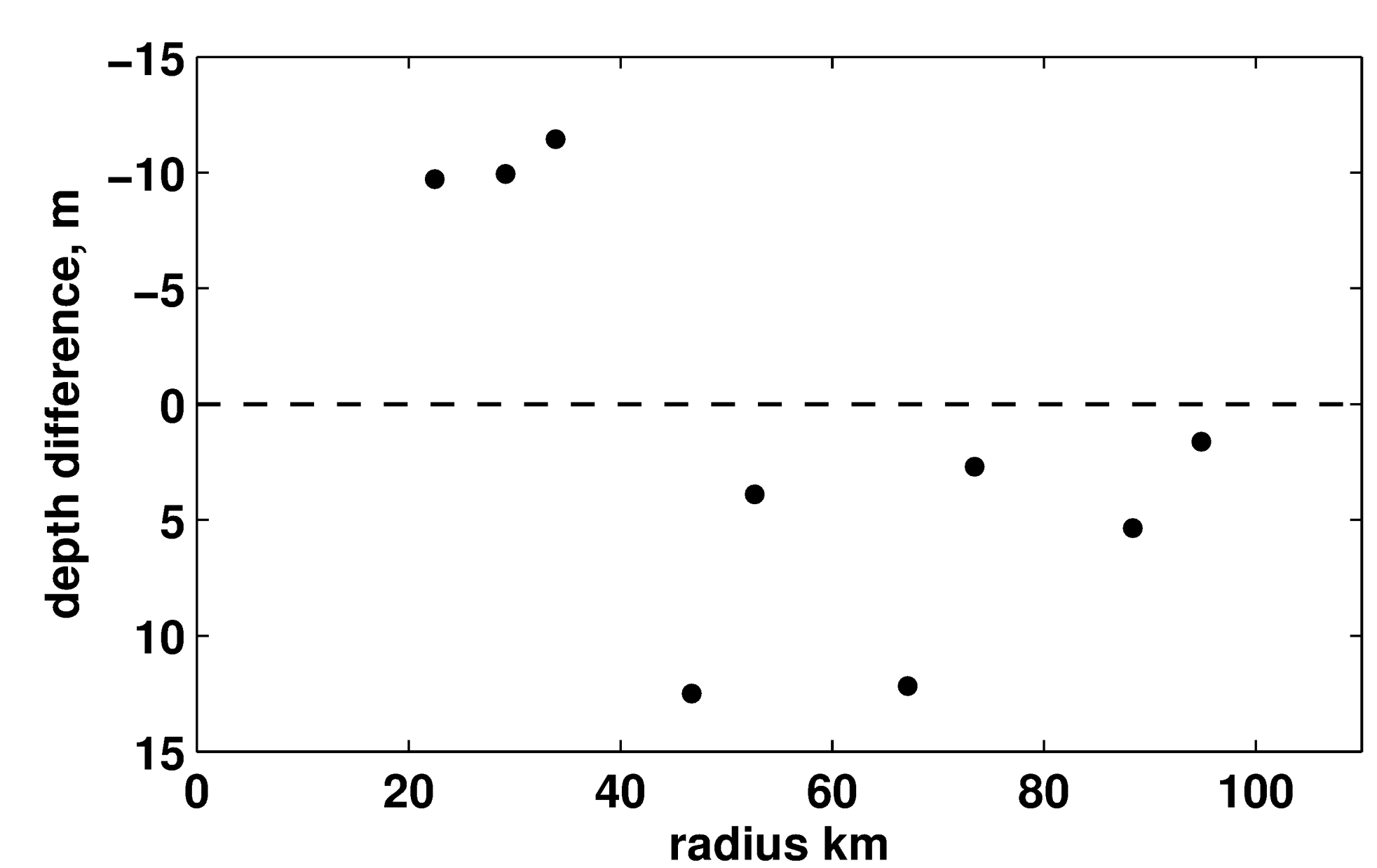




\section{Comparison of the 3 eddies in their mixed layer expression}

Surveyed ocean eddies - mixed layer expression

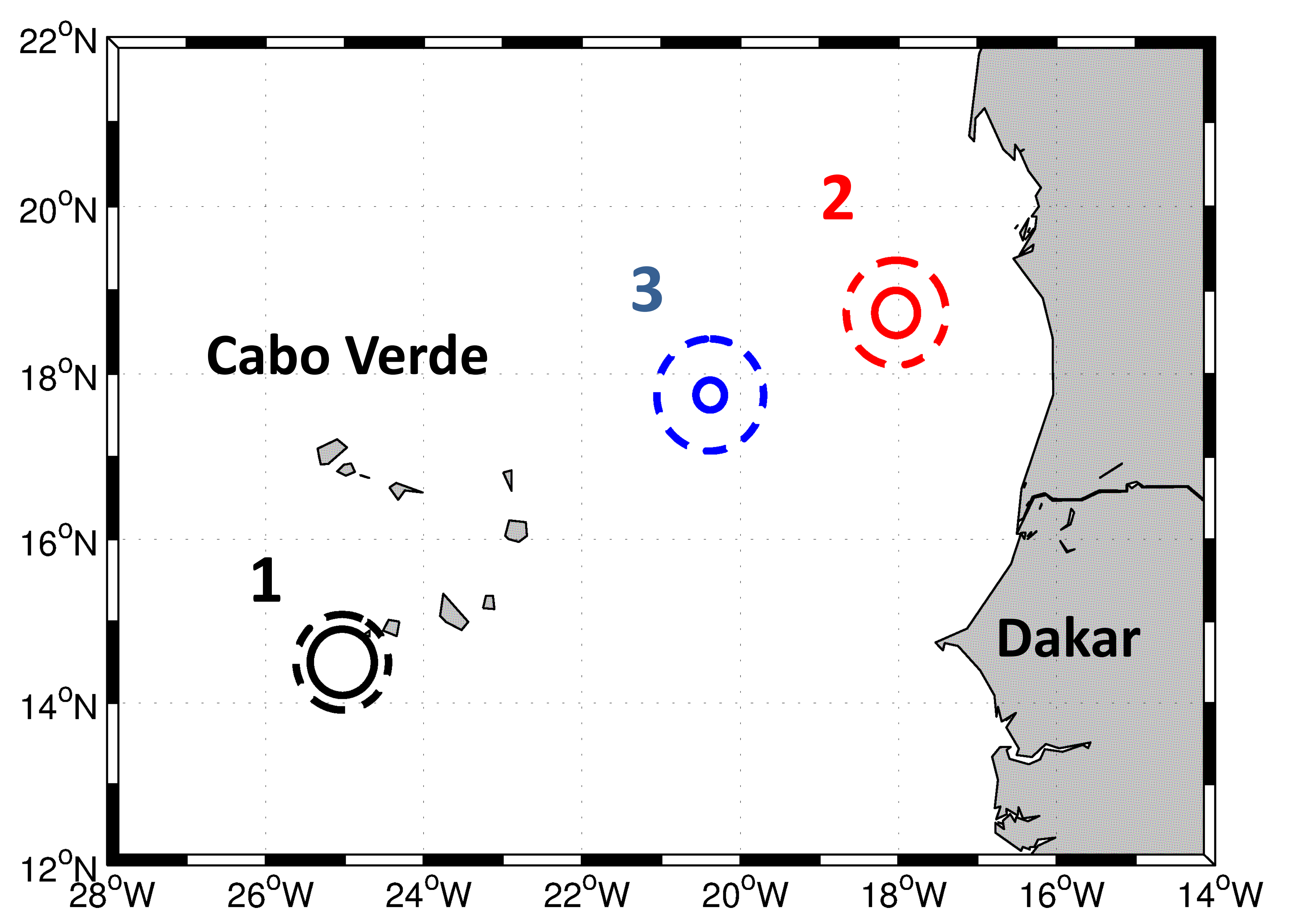

circle of linear
velocity profile
Azimutal velocity vs. radius

(at $15 \mathrm{~m}$ to $45 \mathrm{~m}$ depth)

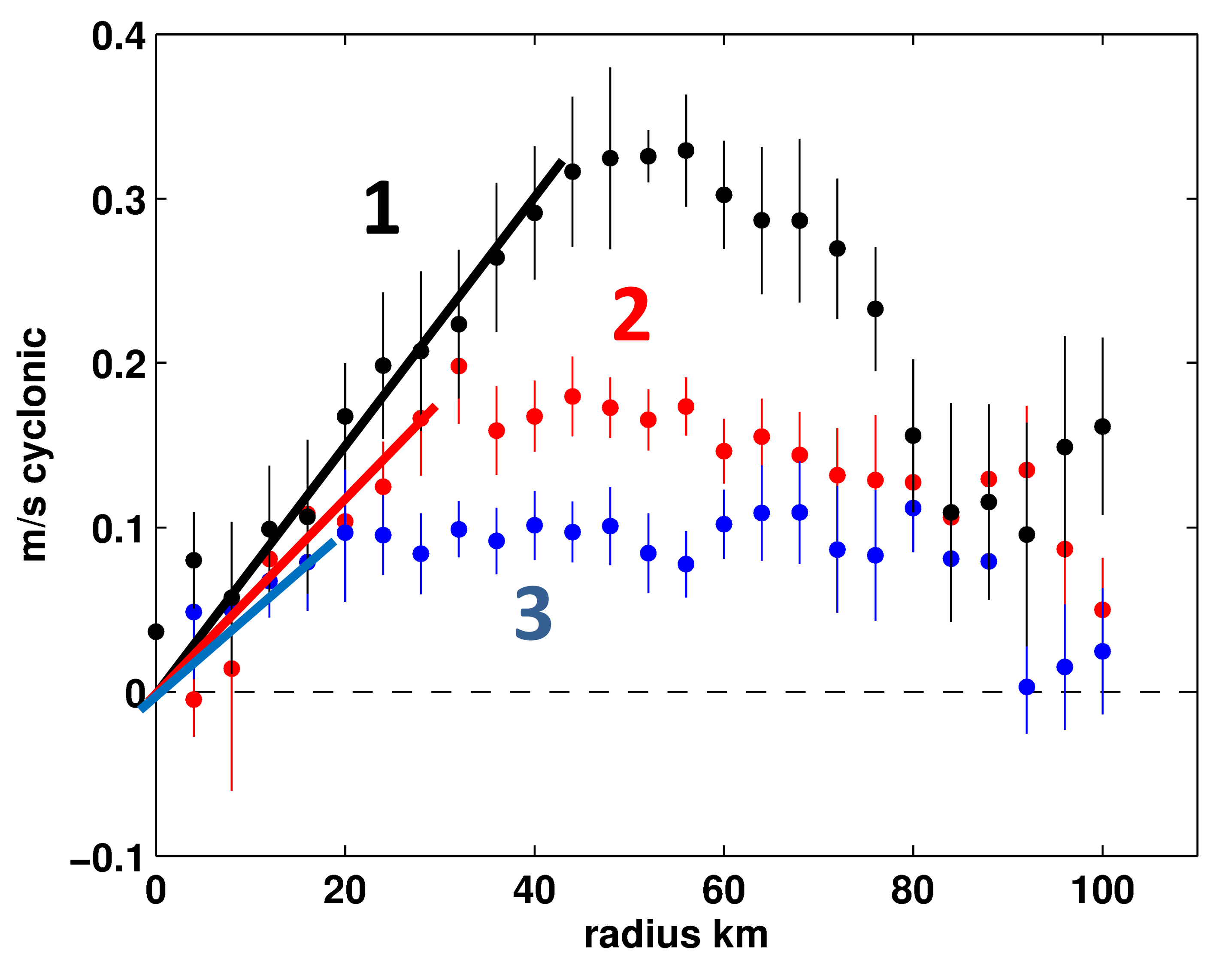

u/Rf for linear velocity part:

1) 0.20

2) 0.13

3) 0.10

In the sequence of Eddy 1-2-3: is the shrinking and weakening of the part in solid body rotation, and the overall decrease of azimutal velocity a sign that the eddies are in different stages of decay? 


\section{Excursion Eddy1: Dynamic change between visit 1 and visit 2}

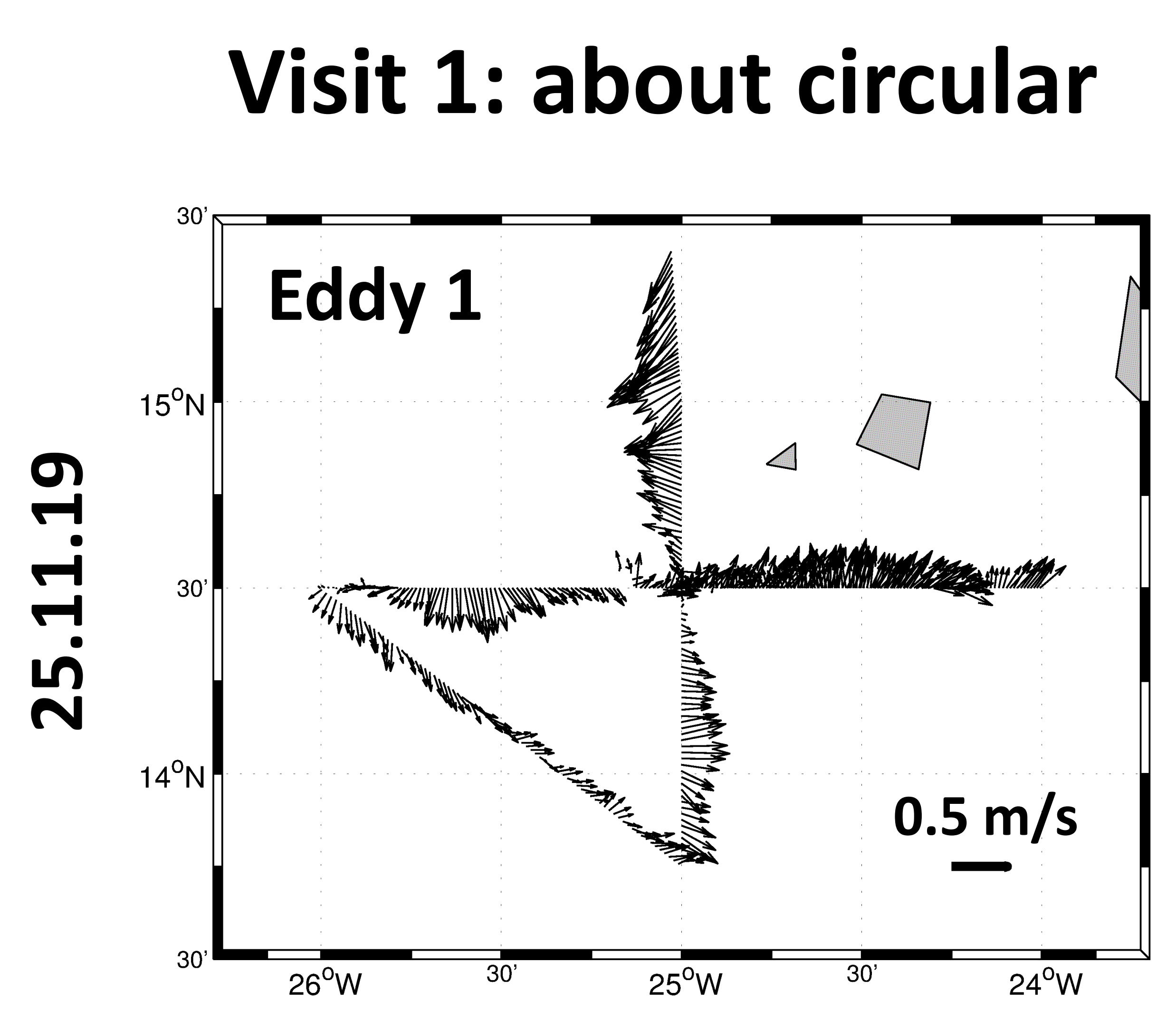

Visit 2: elliptic

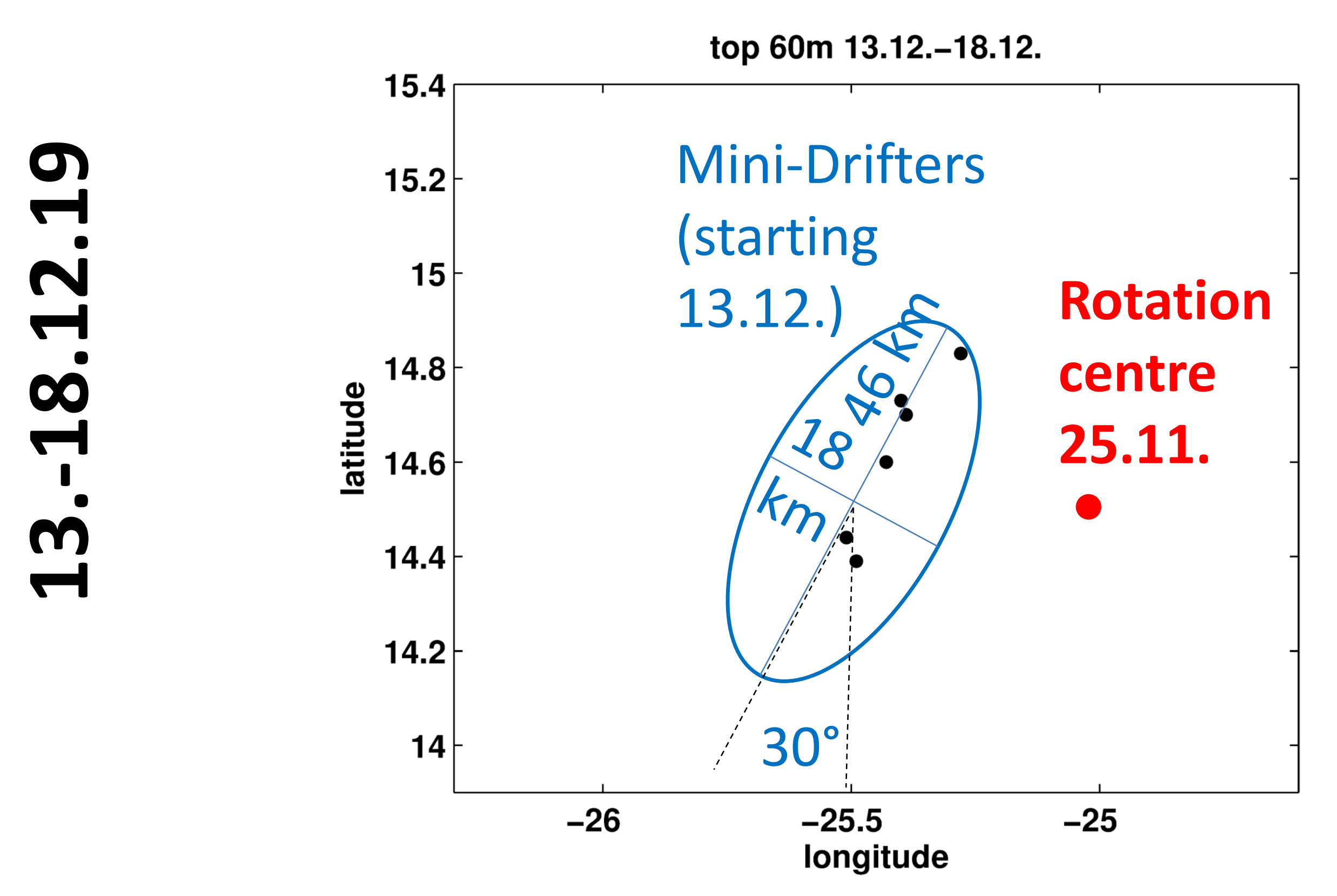

Ellipticity is observed from different

platforms:

Apparent rotation centres of different ADCP sections (black dots) align along a straight line

9 drifter trajectories follow the idealized blue ellipse. After one circulation they leave the area.

Satellite SST 14.12.19

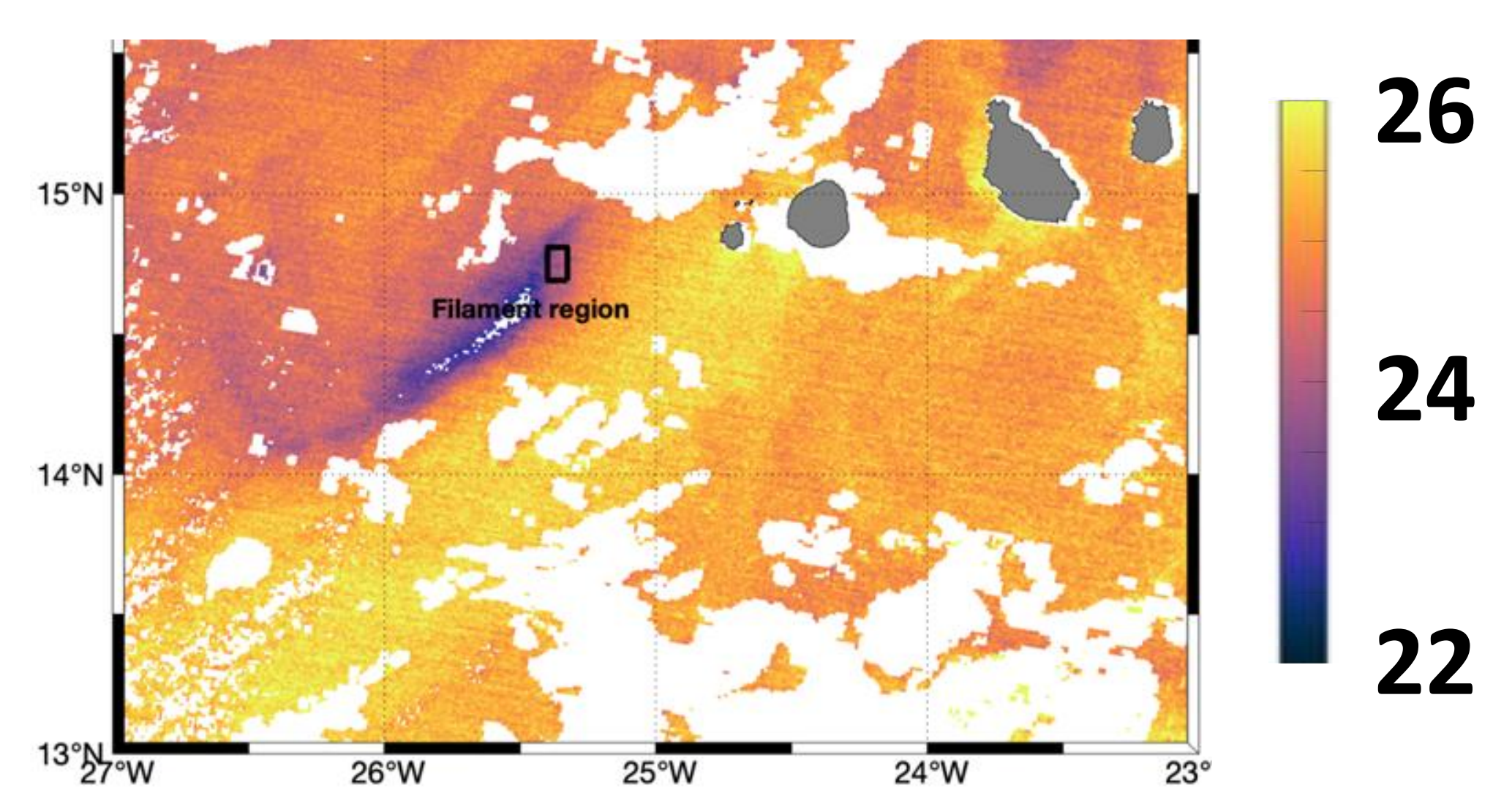

A simple analytical model of ellipse-shaped cyclonic eddies can be derived following Cushman-Roisin, Heil, and Nof (1985) who explored the anticyclonic case. It is a reduced-gravity model with a motionless lower layer. The modeled eddies turn unstable when Ro $=u / R f$ increases beyond a critical value of about 0.21 . They become more and more excentric, and finally collapse into a sheared current.

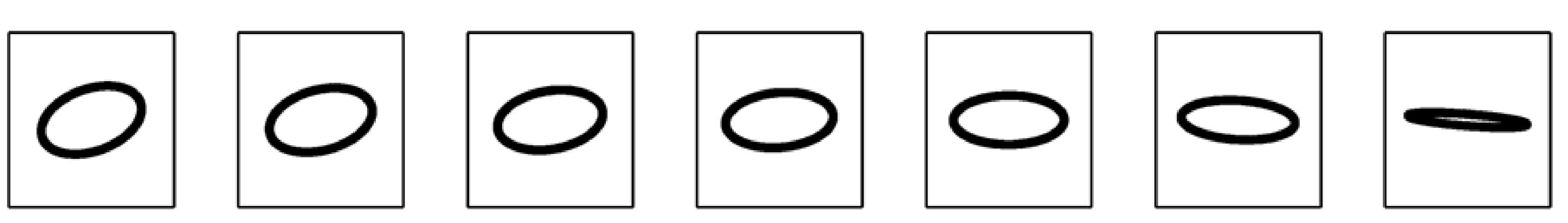

Final stages of an unstable cyclone at $u / R f>0.21$ (no forcing, no friction). Time between panels is $8 \mathrm{~h}$.

Eddy 1 had Ro $=u / R f=0.2$ during the first visit. Strong tradewinds during the following weeks in conjunction with the island wake may have accelerated it further beyond a critical value. However, the model is very simple, and it is yet unclear what exactly happened after visit 2: recovery or decay 


\section{Summary}

REEBUS so far acquired 3 cyclonic eddies in seemingly different decay stages

Multisection ship ADCP currents allow for 3-D localization of eddies. Vorticity structure and a limited divergence structure can be estimated under the assumption of axisymmetry

The example of the weakest eddy suggests that SST is the most robust indicator for the cyclonic eddy core. The vertical position of the Fluorescence maximum relative to the mixed layer depth may be an interesting indicator to explore

The strongest eddy was found in an elliptic shape 3 weeks after the first visit, maybe an indication that it became unstable

\section{References}

Andrae, A.: Comparison of different methods for the detection of mesoscale eddy characteristics in the eastern tropical North Atlantic, Bachelor thesis, Univ. of Kiel, 2020

Bendinger, A.: Characteristics of Mesoscale and Submesoscale Eddies in the Labrador Sea: Observations vs. Model, Master thesis, Univ. of Kiel, 2020

Castelao, G.P., and Johns, W.E.: Sea surface structure of North Brazil Current rings derived from shipboard and moored acoustic Doppler current profiler observations, JGR Oceans, 116, 1-12, 2011

Cushman-Roisin, B., Heil, W.H., Nof, D.: Oscillations and Rotations of Elliptical Warm-Core Rings, JGR, 90, 1175611764,1985 